\title{
Heat Waves in Florida: Climatology, Trends, and Related Precipitation Events
}

\author{
SHEALYNN R. ClOUTIER-BisBEE \\ Meteorology Program, Applied Aviation Sciences Department, Embry-Riddle Aeronautical University, \\ Daytona Beach, Florida \\ AJAY RAGHAVENDRA \\ Department of Atmospheric and Environmental Sciences, University at Albany, \\ State University of New York, Albany, New York \\ SHAWN M. MiLRAD \\ Meteorology Program, Applied Aviation Sciences Department, Embry-Riddle Aeronautical University, \\ Daytona Beach, Florida
}

(Manuscript received 24 June 2018, in final form 22 December 2018)

\begin{abstract}
Heat waves are increasing in frequency, duration, and intensity and are strongly linked to anthropogenic climate change. However, few studies have examined heat waves in Florida, despite an older population and increasingly urbanized land areas that make it particularly susceptible to heat impacts. Heavy precipitation events are also becoming more frequent and intense; recent climate model simulations showed that heavy precipitation in the three days after a Florida heat wave follow these trends, yet the underlying dynamic and thermodynamic mechanisms have not been investigated. In this study, a heat wave climatology and trend analysis are developed from 1950 to 2016 for seven major airports in Florida. Heat waves are defined based on the 95th percentile of daily maximum, minimum, and mean temperatures. Results show that heat waves exhibit statistically significant increases in frequency and duration at most stations, especially for mean and minimum temperature events. Frequency and duration increases are most prominent at Tallahassee, Tampa, Miami, and Key West. Heat waves in northern Florida are characterized by large-scale continental ridging, while heat waves in central and southern Florida are associated with a combination of a continental ridge and a westward extension of the Bermuda-Azores high. Heavy precipitation events that follow a heat wave are characterized by anomalously large ascent and moisture, as well as strong instability. Light precipitation events in northern Florida are characterized by advection of drier air from the continent, while over central and southern Florida, prolonged subsidence is the most important difference between heavy and light events.
\end{abstract}

\section{Introduction}

As the global climate has warmed, extreme weather events such as heat waves, droughts, and extreme precipitation events have increased in frequency, duration, and/or intensity (e.g., Coumou and Rahmstorf 2012; IPCC 2013). Heat waves have been identified as one of the most strongly linked phenomena to anthropogenic climate change (e.g., Perkins et al. 2012). They are often referred to as the "silent meteorological killer" (Perkins 2015; Mora et al. 2017), particularly in locations with aging populations or underdeveloped infrastructure. For example, the 2003 European heat wave resulted in

Corresponding author: Shawn M. Milrad, milrads@erau.edu more than 70000 deaths, while the 2010 Russian heat wave killed more than 50000 people (Coumou and Rahmstorf 2012). Mora et al. (2017) conducted a global analysis of lethal heat waves since 1980 and found that $30 \%$ of the human population is currently at risk of exposure to heat conditions that exceed a lethal threshold. Even worse, they reported that the at-risk population increases to $48 \%$ and $74 \%$ under greenhouse gas emission reduction and growth scenarios, respectively.

It is not just daytime maximum temperatures that affect human life and health; Nissan et al. (2017) pointed out that anomalously warm nighttime minimum temperatures have been linked to increased mortality and detrimental health effects in high-impact heat waves across the globe during the past few decades. Duration 
is also thought to be crucial; although one day of extreme warmth typically does not produce major impacts, periods of three days or more pose a huge threat (e.g., Nissan et al. 2017). For more details on specific past heat wave events, mechanisms, and impacts, the reader is referred to the review papers of Perkins (2015) and Mora et al. (2017).

In the United States, the ratio of record daily warm to cold temperatures has been increasing rapidly since the 1970 s and is projected to be $20: 1$ by the mid-twenty-first century (Meehl et al. 2009; Diffenbaugh and Ashfaq 2010). However, the southeast United States was relatively slow to warm, and at times cooled, during the latter half of the twentieth century (e.g., Meehl et al. 2012). This "warming hole" was caused by a multitude of factors including natural variability, increased cloud cover, and land surface processes (Meehl et al. 2012; Rogers 2013; Partridge et al. 2018). Yet even during the warming hole era, heat waves in the southeast United States still increased in frequency, duration, and intensity (Smith et al. 2013). Furthermore, the southeast United States has experienced a distinct warming trend since the start of the twenty-first century (Meehl et al. 2012; Smith et al. 2013). Smith et al. (2013) found that for all U.S. regions during 1979-2011, the southeast United States had the largest land area percentage (12\%) that experienced statistically significant increases in heat wave frequency and number of heat wave days per year. Recent research has shown that during the next few decades, continued warming and associated increases in heat wave frequency, duration, and intensity are projected to continue across most of the United States, including the southeast (e.g., Herrera-Estrada and Sheffield 2017; Guirguis et al. 2018).

Despite its maritime climate, Florida is not immune to heat waves, but there have been relatively few studies on such. Heat wave dangers can be amplified in Florida because of its relatively large older population. Keellings and Waylen $(2014,2015)$ explored heat wave trends during the latter half of the twentieth century and found that heat waves across the state became more frequent, longer, and stronger with time. Recently, Raghavendra et al. (2019, hereafter R19) compared current Florida summer heat waves to projected changes under the RCP8.5 high-emissions scenario (Riahi et al. 2011) using highresolution convection-allowing numerical model simulations (e.g., Dai et al. 2019; Liu et al. 2017) and found that by the end of the twenty-first century, heat wave frequency will triple with a sixfold duration increase. The heat wave definitions, methodology, and observed data of R19 were based on the current study (section 2).

Florida's large older population and rapidly growing urban areas, parts of which still lack air conditioning, make it quite susceptible to the impacts of heat waves on human life and health (Florida Department of Health 2015). Urbanization has been steadily increasing throughout the large metropolitan areas of southeastern Florida (Miami-Fort Lauderdale-West Palm Beach), central Florida (Orlando), and Tampa Bay (Tampa-ClearwaterSaint Petersburg). Many studies have shown that heat waves can be enhanced by the urban heat island effect (e.g., Greene et al. 2011; Ramamurthy and Bou-Zeid 2017; Wouters et al. 2017), which in turn is amplified by heat waves. A recent high-resolution modeling study by Ortiz and Gonzalez (2018) found that the urban heat island intensified by as much as $4^{\circ} \mathrm{C}$ during a heat wave in New York City. Furthermore, the contributions of the urban heat island to temperatures during the heat wave were considerably larger at night (Ortiz and Gonzalez 2018), when adverse health effects can be the worst (e.g., Nissan et al. 2017).

Most studies concur that anthropogenic warming has increased the frequency and intensity of heavy precipitation events. This is primarily due to the marked increase in atmospheric water vapor content associated with warmer temperatures, which is projected to continue in the coming decades (e.g., Kunkel et al. 2013; Fischer and Knutti 2015). To that end, Dai et al. (2019) projected an increase in the frequency of heavy and extreme precipitation events over the continental United States during the late twenty-first century, while Prein et al. (2017) reported an increase in extreme hourly precipitation intensities over the past few decades.

In accordance with other recent precipitation projection studies, R19 found that, while there may be a slight decrease in mean precipitation over Florida by the late twenty-first century, heavy precipitation events will become more frequent and intense, particularly in the 1-3 days immediately following a heat wave. The linkages between heat waves and heavy precipitation are important in a maritime tropical climate such as Florida, yet the two phenomena have rarely been studied together (R19). To that end, recent studies by Schoof et al. (2017) and Li et al. (2018) found that, while humidity is often a key component in heat wave impacts, particularly at low latitudes ( $\mathrm{Li}$ et al. 2018), it is rarely included in heat wave metrics. Schoof et al. (2017) also found that all U.S. regions except the northern plains have experienced increases in both temperature and equivalent temperature (a combination of heat and humidity) related heat waves. For Florida, elucidating connections between summer heat waves and subsequent precipitation is vital because much of the state's rainfall falls during the warm season (e.g., Schwartz and Bosart 1979), and a warmer climate will impact the frequency and intensity of heavy precipitation. 
This study establishes an objective heat wave metric, climatology, and trend analysis for major cities in Florida during summers from 1950 to 2016. In addition, linkages between heat waves and subsequent precipitation events are assessed. Specific objectives include the following:

- The development of objective heat wave metrics based on daily station temperature data. The current definition of a heat wave according to the American Meteorological Society (AMS) Glossary of Meteorology is "a period of abnormally and uncomfortably hot and usually humid weather" (American Meteorological Society 2018). Currently, there is no universally accepted definition of heat waves (Perkins et al. 2012; Perkins 2015; Nissan et al. 2017; Schoof et al. 2017), with different approaches used for length, magnitude, and temperature metrics.

- Establishment of a heat wave climatology and trend analysis from 1950 to 2016 for seven major Florida airports. Specific aspects that are addressed in the trend analysis include frequency, duration, and subregional differences.

- An analysis of the synoptic-scale circulation features associated with Florida heat waves, as well as an investigation of linkages between heat waves and subsequent precipitation events. This association is particularly important to Florida's weather and climate, given the presence of two adjacent large moisture sources (Atlantic Ocean, Gulf of Mexico).

- An analysis of the dynamic and thermodynamic mechanisms for and differences between heavy and light precipitation events that follow a Florida heat wave, using an ingredients-based methodology (lift, moisture, instability) for flash flooding (Doswell et al. 1996).

The remainder of this paper is organized as follows: Section 2 provides an overview of data and heat wave definitions, heat wave characteristics are discussed in section 3 , and the large-scale characteristics of heat waves and precipitation events are analyzed in section 4 . Finally, conclusions and potential avenues of future work are presented in section 5 .

\section{Data and methods}

Heat wave event identification and statistical analyses were performed for seven major airports in Florida (Fig. 1) using temperature data from the Applied Climate Information System (ACIS; DeGaetano et al. 2015). ACIS is a data portal developed and maintained by the NOAA regional climate centers and provides easily accessible quality-controlled station climate data. Daily maximum, minimum, and mean temperatures were downloaded from ACIS for 1950-2016. The seven airports in Fig. 1 were chosen for their long station records as well as being representative of the most populous areas in Florida. Although Key West (KEYW) has a relatively small population $(\sim 27000)$, it is unique in that it has a long reliable station record, minimal urbanization, and is surrounded by water.

According to the Perkins (2015) review paper, most studies use only one of the following variables for a heat wave metric: maximum, minimum, mean, or apparent temperature (heat index). For Florida, Keellings and Waylen (2014) applied a bivariate heat wave index, using both maximum and minimum temperatures to define heat wave events. The heat wave metric in this paper uses multiple temperature variables individually (maximum, minimum, and mean temperature) and a single percentile-based threshold.

Nissan et al. (2017) evaluated multiple heat wave indices in Bangladesh based on health and mortality impacts as well as operational forecast concerns; they determined that the best heat wave definition was $\geq 3$ days during which a daily temperature variable (i.e., maximum, minimum, mean) exceeded the 95th percentile. Although heat wave definitions vary throughout the literature, many studies have used the 3-day and 95th percentile thresholds (Perkins 2015). As such, we use it here and calculated the 95th percentile for maximum, minimum, and mean daily temperatures. We also tested the 99th percentile but found that only a small number of events exceeded the 99th percentile. R19 tested both the 92.5th and 97.5th percentiles and found minimal differences among all thresholds. Heat wave events were identified separately for each of the three temperature variables in summer (JuneAugust) only.

To be considered a heat wave event, the daily maximum, minimum, or mean temperature at a station had to exceed the 95th percentile for three consecutive days with a gap of at least four consecutive days between events. The 4-day gap criterion was instituted to ensure synoptic-scale independence for precipitation events that followed a heat wave (section 4). Using the heat wave metric for each temperature variable, trends in frequency and duration as well as subregional differences were investigated (section 3).

Precipitation events (section 4) were analyzed using the hourly National Centers for Environmental Prediction (NCEP) stage IV dataset (Lin and Mitchell 2005), which is produced for the contiguous United States on a 4-km grid and incorporates rain gauge and radar data. Mass field composites during both the heat wave and precipitation periods were produced using the European Centre for Medium-Range Weather Forecasts (ECMWF) interim reanalysis (ERA-Interim; Dee et al. 2011), which 


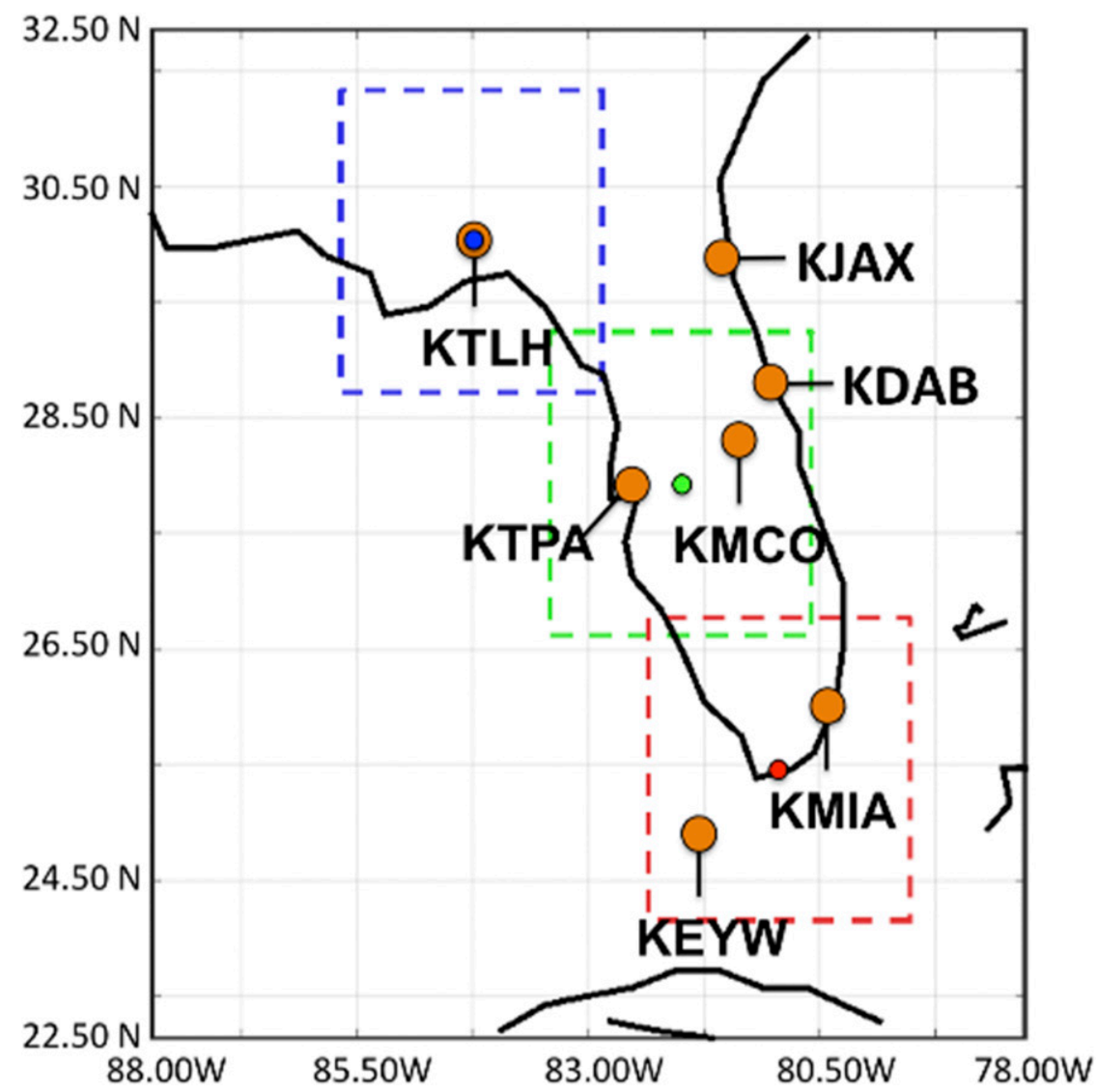

FIG. 1. Map of Florida showing the seven airports used in this study [orange dots; four-letter International Civil Aviation Organization (ICAO) station identifiers written in black]. The dashed boxes show the $3^{\circ} \times 3^{\circ}$ areas used to calculate area-averaged precipitation for the original north (blue), central (green), and south (red) sectors. The dots matching the color of each respective box identify the center of that box.

has a spectral T255 horizontal resolution corresponding to a $\sim 79-\mathrm{km}$ grid spacing, a temporal resolution of $6 \mathrm{~h}, 60$ vertical levels, and is available from 1979 to the present.

The heat wave statistical analyses and Figs. 1-3 were produced using MathWorks MATLAB. The precipitation analysis and synoptic composites that follow in Figs. 4-10 were created using the General Meteorological Package (GEMPAK), version 7.4.1, updated from the original package devised by Koch et al. (1983).

\section{Heat wave characteristics}

\section{a. Frequency}

To investigate summer heat wave frequency, bar graphs of heat wave events for each temperature variable are shown in Fig. 2, with linear trend lines and $p$ values plotted in each panel. Trends are considered statistically significant when $p \leq 0.05$. We also ran the nonparametric Mann-Kendall (MK) test to evaluate the significance of the linear trends, and results are also shown in the inset text in each panel (Fig. 2). For the sake of space, Daytona Beach (KDAB) is not shown, but its heat wave statistics are very similar to Orlando (KMCO).

While Tallahassee (KTLH), KMCO, Tampa (KTPA), Miami (KMIA), and KEYW exhibit statistically significant increases in minimum and mean temperature heat waves according to $p$ values (Figs. 2b-f), Jacksonville (KJAX) does not (Fig. 2a). In fact, KJAX exhibits a statistically significant heat wave decrease in all three temperature variables, particularly in minimum temperature events $\left(-0.166\right.$ events decade $\left.{ }^{-1}\right)$ since 1950. KJAX also saw more heat waves in the 1950s and 1960s than since 2000, regardless of temperature variable (Fig. 2a). Additional diagnostics (not shown) found that the 95th percentiles of all three temperature variables were approximately $0.6^{\circ} \mathrm{C}$ colder during the most recent 17 years compared to the first 17 years of our climatology. This recent cold bias is largely due to 
a) KJAX

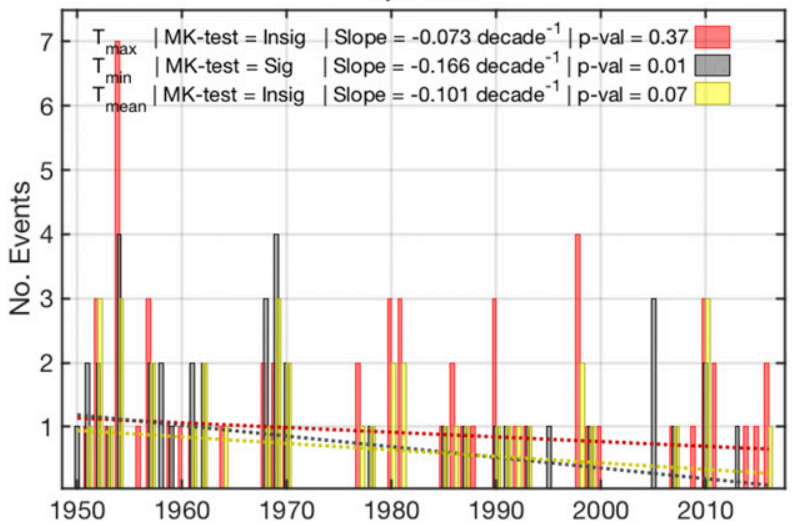

c) KMCO

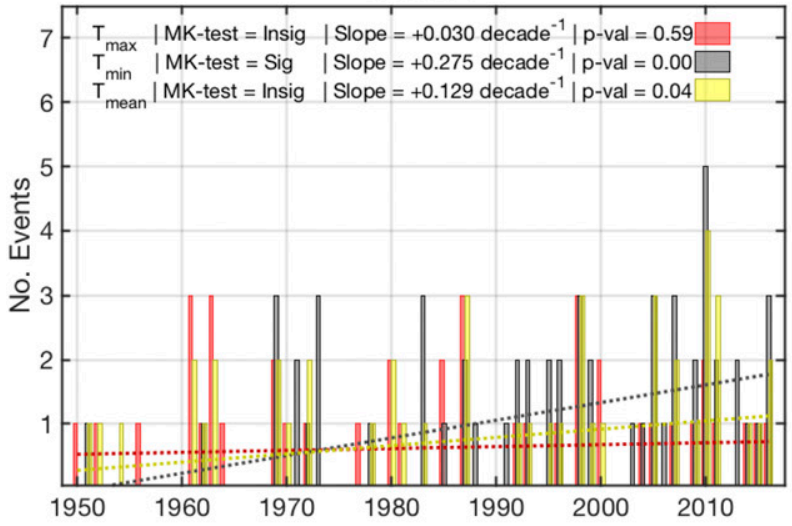

e) KMIA

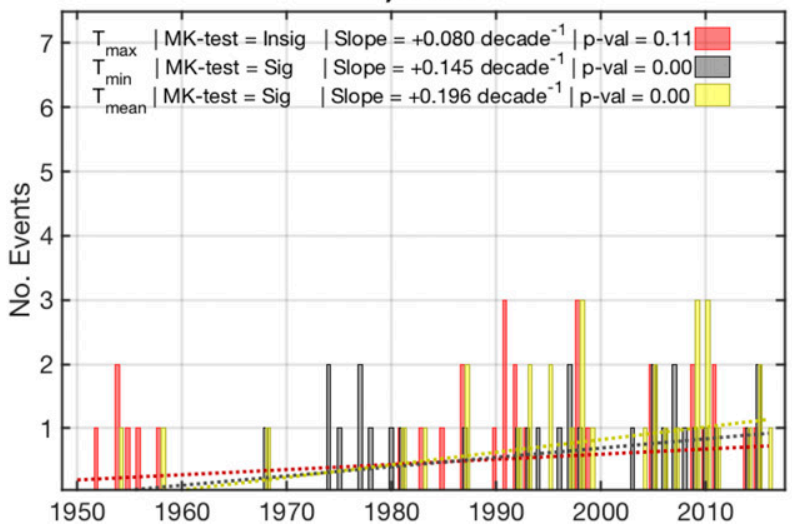

b) KTLH

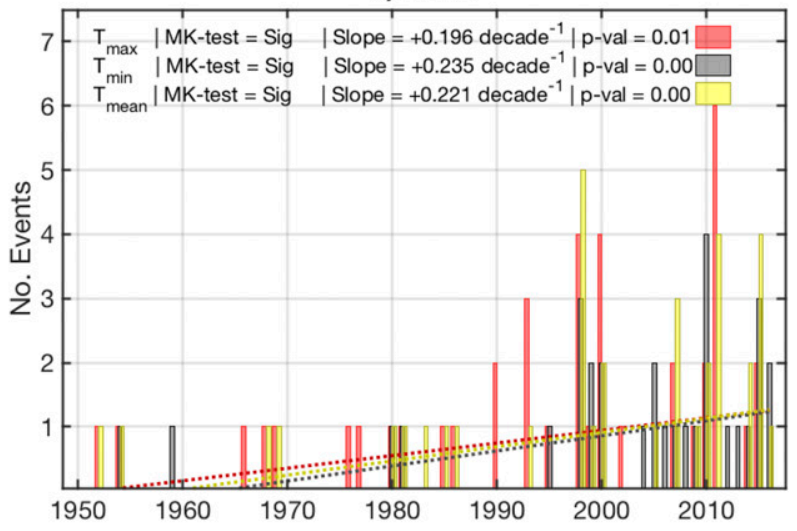

d) KTPA

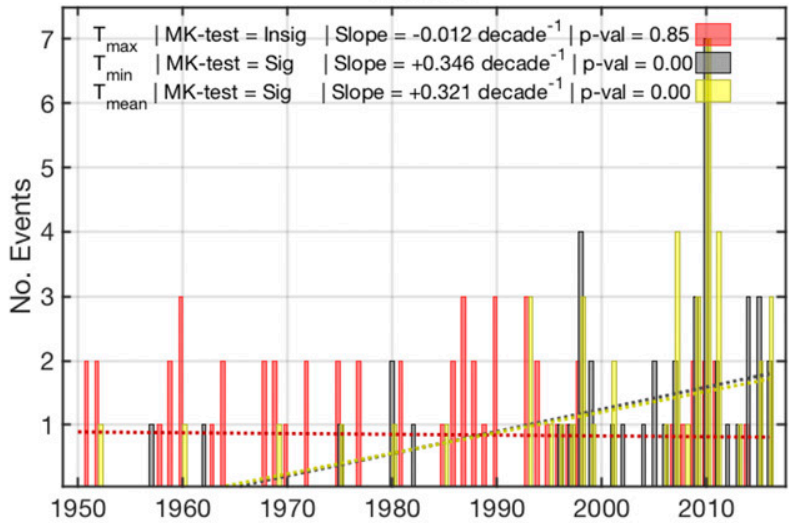

f) KEYW

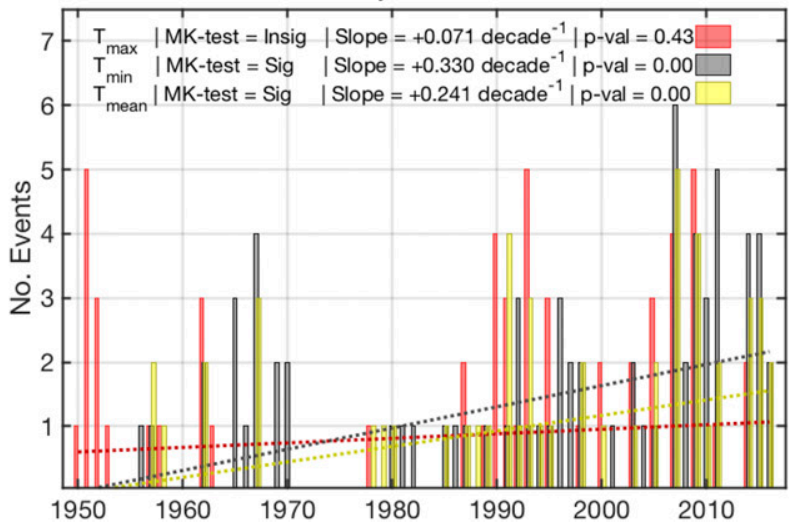

FIG. 2. Bar graphs depicting the number of summer heat wave events (vertical axis) each year from 1950 to 2016 at (a) KJAX, (b) KTLH, (c) KMCO, (d) KTPA, (e) KMIA, and (f) KEYW. Heat waves defined based on the 95th percentile of daily maximum, minimum, and mean temperatures (section 2) are plotted in red, gray, and yellow, respectively. Linear trends (events decade ${ }^{-1}$ ), as well as $p$ values based on the Student's $t$ test and the MK significance test for the linear trends are plotted at the top right of each panel. Trends are deemed statistically significant according to the Student's $t$ test when $p \leq 0.05$.

a change in KJAX location in 1968. Prior to 1968, KJAX was located only $8 \mathrm{~km}$ from downtown Jacksonville and on the banks of the Saint John's River. The post-1968 (and current) airport location, however, is located approximately $20 \mathrm{~km}$ north-northwest of downtown
Jacksonville, in a rural forested area of Duval County. As shown by, for example, Ortiz and Gonzalez (2018) and Wouters et al. (2017), urban heat islands can have pronounced impacts on heat wave statistics, particularly at night. In addition, the old KJAX airport location 
near a river also likely contributes to the warm bias during the first part of the climatology. KJAX is the only station in this study that experienced a location change during our climatology period, as the other six stations have homogeneous records.

Other than KJAX, all stations exhibit statistically significant increasing minimum and mean temperature heat wave frequencies according to $p$ values (Fig. 2). The MK test also detected statistically significant increases in minimum and mean temperature heat waves everywhere except KMCO mean temperature heat waves (Fig. 2c), which has a $p$ value of 0.04. Maximum temperature heat waves increase in frequency at KTLH (Fig. 2b), KMCO (Fig. 2c), KMIA (Fig. 2e), and KEYW (Fig. 2d), but the increase is only statistically significant ( $p$ value and MK test) at KTLH $\left(+0.196\right.$ events decade ${ }^{-1}$; $p=0.01)$. As such, KTLH is the only station to exhibit statistically significant positive trends for all temperature variables (Fig. 2b). This suggests that the climatological sea breezes and larger warm-season precipitation amounts may mitigate increases in daytime heat waves throughout the Florida Peninsula (central and south Florida). Specifically, afternoon sea breezes can provide a natural limitation on daily maximum temperatures at coastal or near-coastal locations because they initiate and cool the surface temperature as soon as the surface temperature exceeds the sea surface temperature (SST) of the adjacent waters. In addition, in the Florida Peninsula, larger climatological precipitation can limit daily maximum temperatures through increased cloud cover (e.g., Gentry and Moore 1954; Schwartz and Bosart 1979). However, KTLH is located in the Florida Panhandle where there is only one sea breeze and thus less climatological precipitation in summer. Schwartz and Bosart (1979) and Blanchard and Lopez (1985) found that unlike the panhandle, approximately half of the Florida Peninsula's annual rainfall occurs from May to September. In addition, Burpee and Lahiff (1984) reported that $35 \%-40 \%$ of warm-season rainfall occurs purely as a result of sea-breeze-related processes in the Florida Peninsula.

KMCO, KTPA, and KMIA have experienced rapid urbanization over the past few decades (Keellings and Waylen 2014), which tends to have larger impacts on minimum temperatures (e.g., Perkins 2015; Nissan et al. 2017; Ortiz and Gonzalez 2018). However, large statistically significant increases in daily minimum and mean temperature heat waves $\left(+0.33\right.$ and +0.241 events decade ${ }^{-1}$, respectively) at KEYW (Fig. 2f) suggest relatively minimal impacts from urbanization. Key West's population $(\sim 27000)$ has been relatively constant since the late 1960s and decreased slightly since 1950 . To that point, KEYW (Fig. 2f) exhibits the second-largest (after KTPA) positive trends in minimum and mean heat wave frequency of any station, including KMCO (Fig. 2c) and KMIA (Fig. 2e), which are both located in extremely urban areas.

KTPA and KEYW are both located within $1 \mathrm{~km}$ of large warm bodies of water. These stations exhibit the two largest statistically significant positive trends in minimum $(+0.346$ and +0.330 events decade ${ }^{-1}$ at KTPA and KEYW, respectively) and mean $\left(+0.321\right.$ and +0.241 events decade $^{-1}$ at KTPA and KEYW, respectively) temperature heat wave frequency. KTPA and KEYW also have the two largest differences between maximum and minimum temperature heat wave frequency trends (Figs. 2d,f). Although it is not a focus of this paper, the disproportional increases in daily minimum temperature heat waves at KTPA and KEYW, particularly since the 1990s, could be due to warmer SSTs. SST increases in waters adjacent to Florida, especially the Gulf of Mexico, were found by Little et al. (2015) and Taylor and Clarke (2018). Warmer SSTs promote more evaporation and thus could increase atmospheric water vapor, which tends to have larger impacts on nighttime temperatures.

\section{b. Duration}

Because the background temperature distribution is changing throughout our climatology period while our heat wave definition (95th percentile) is not, heat wave intensity changes are difficult to evaluate (e.g., Perkins 2015) and are not discussed here. However, Keellings and Waylen $(2014,2015)$ and R19 found that heat wave intensity in Florida has increased and will continue to increase by the end of the twenty-first century, respectively. Here, we instead focus on describing trends in heat wave duration, plotted in Fig. 3.

We calculated the mean duration of each heat wave to create the bar graphs in Fig. 3. Heat wave duration has increased for all temperature variables at all stations except KJAX (see section 3a), although not all increases are statistically significant (Fig. 3). As with heat wave frequency, only KTLH exhibits statistically significant duration increases for all three variables (Fig. 3b). According to $p$ values, maximum temperature heat wave duration increases are only statistically significant at KTLH $\left(+0.322\right.$ days decade $\left.{ }^{-1}\right)$ and KMCO $\left(+0.371\right.$ days decade $\left.{ }^{-1}\right)$, although the MK test only detects significance at KTLH (Figs. 3b,c). Meanwhile, minimum and mean temperature heat wave duration increases are statistically significant everywhere except KJAX and $\mathrm{KJAX} / \mathrm{KMCO}$, respectively (Fig. 3). The increase in KMCO mean temperature heat wave duration is just barely insignificant, with a $p$ value of 0.07 (Fig. 3c).

As for heat wave frequency, we suggest that the pronounced heat wave duration increases $(+0.322,+0.532$, and +0.395 days decade $^{-1}$ for maximum, minimum, and mean temperature heat waves, respectively) at KTLH 
a) KJAX

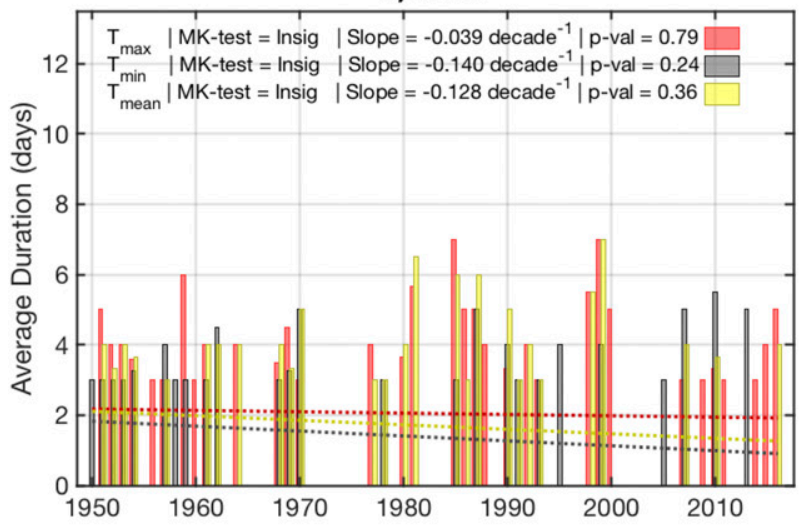

c) $\mathrm{KMCO}$

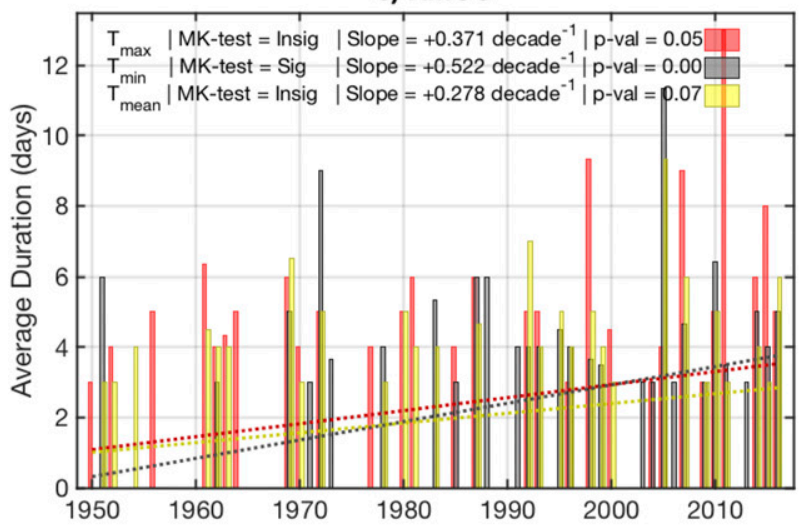

e) KMIA

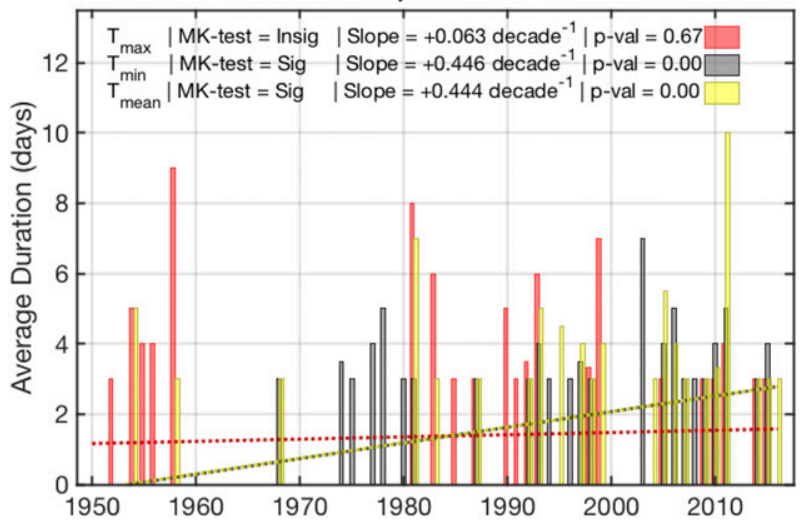

b) KTLH

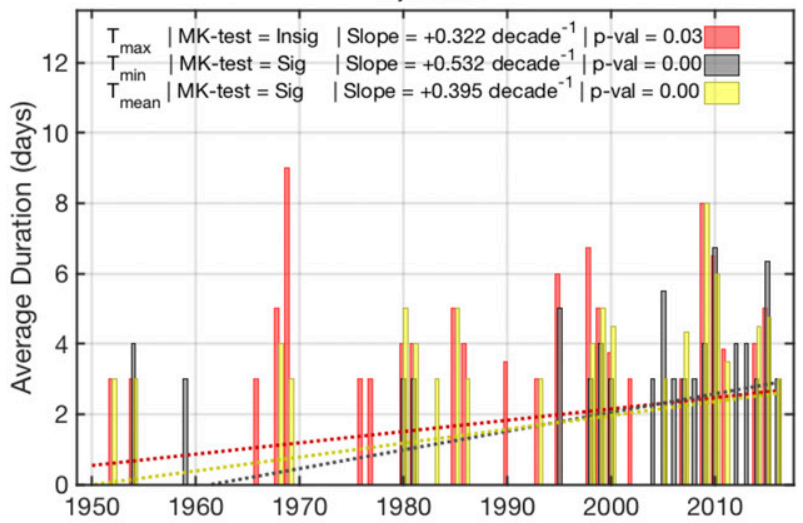

d) KTPA

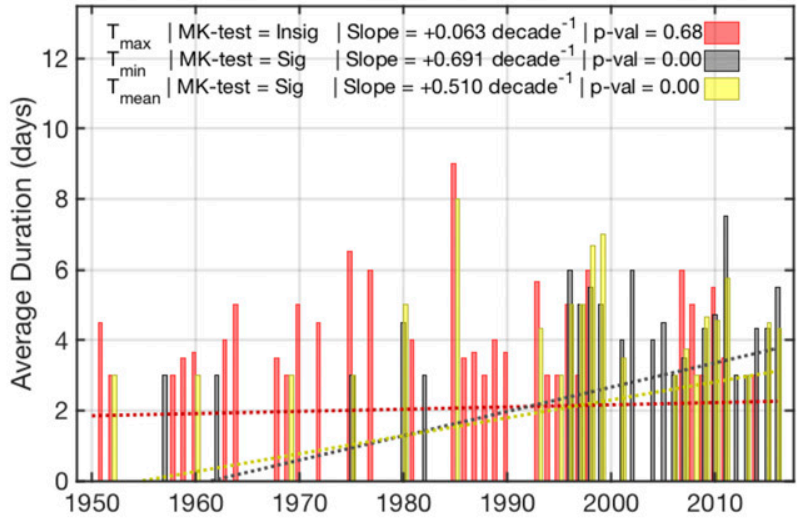

f) KEYW

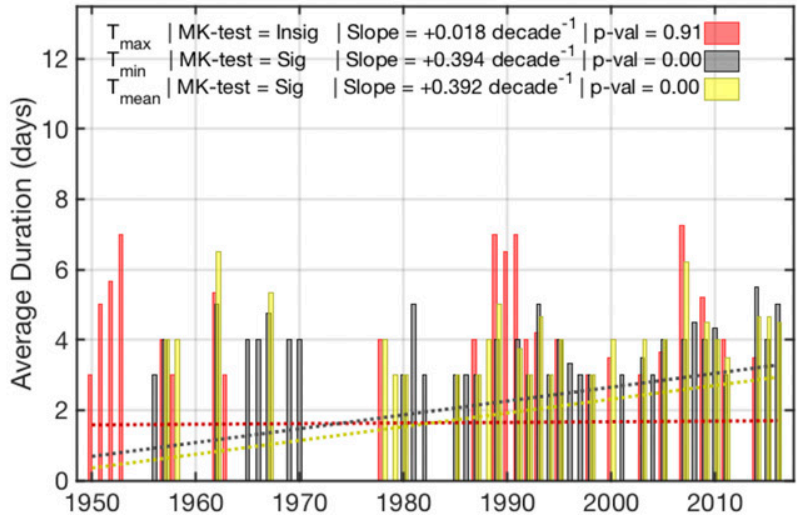

FIG. 3. As in Fig. 2, but for summer heat wave (1950-2016) average duration (days, vertical axis).

(Fig. 3b) are due to a combination of Tallahassee being located relatively far from a coast and in a subregion that receives less warm-season rainfall than the Florida Peninsula (Schwartz and Bosart 1979). That is, KTLH is less frequently affected by the cooling effects of the afternoon sea breeze and also sees less cloud cover as a result of less warm-season precipitation (e.g., Gentry and Moore 1954; Schwartz and Bosart 1979). Figures 3d-f show large and statistically significant duration increases in minimum and mean temperature heat waves $(+0.691$ and +0.51 days decade $\left.{ }^{-1}\right)$ at KTPA, KMIA $(+0.446$ and +0.444 days decade $\left.^{-1}\right)$, and KEYW $(+0.394$ and +0.392 days decade $\left.{ }^{-1}\right)$. At these three stations, mean and minimum temperature heat waves have drastically increased in frequency and duration, supporting the hypothesis that warmer SSTs and increased water vapor are resulting in larger increases in nighttime minimum temperatures at coastal Florida locations. Causality between 
TABLE 1. For heavy and light precipitation events (2002-16) in the north and central-south sectors: NCEP stage IV 3-day area-averaged precipitation range $(\mathrm{mm})$, percentile range, median $(\mathrm{mm})$, and mean $(\mathrm{mm})$.

\begin{tabular}{lccrr}
\hline \hline \multicolumn{1}{c}{ Sector (category) } & Range $(\mathrm{mm})$ & Percentile range & Median $(\mathrm{mm})$ & Mean $(\mathrm{mm})$ \\
\hline North (heavy) & $18.4-38.4$ & 51 st-100th & 26.2 & 28.2 \\
North (light) & $3.0-16.7$ & $1 \mathrm{st}-50$ th & 7.8 & 8.5 \\
Central-south (heavy) & $15.1-99.1$ & 72nd-100th & 23.0 & 27.8 \\
Central-south (light) & $1.6-10.7$ & 1 st-28th & 6.8 & 6.7
\end{tabular}

warmer SSTs and increasing nighttime temperatures along the Florida coasts were shown by Little et al. (2015).

\section{Precipitation events and synoptic analysis}

\section{a. Event identification}

NCEP stage IV precipitation (Lin and Mitchell 2005) data were used to examine the 72-h (3 day) period following our heat waves, starting at 1200 UTC on the final day of a heat wave. Precipitation event analysis was limited to heat waves from 2002 to 2016 because of stage IV data availability. To eliminate duplicate events, only daily mean temperature heat waves were selected for analysis. Area-averaged 72 -h precipitation was calculated over $3^{\circ} \times 3^{\circ}$ boxes for three Florida sectors: north, central, and south (Fig. 1). The north sector was centered on KTLH, the central region centered halfway between KMCO and KTPA, and the south region centered between KMIA and KEYW (Fig. 1).

The primary objectives of the composite precipitation analysis are to elucidate the (i) synoptic-scale precursors and characteristics of Florida heat waves and subsequent precipitation events and (ii) the differences in environmental ingredients between heavy and light precipitation events. Better understanding of environmental characteristics and ingredients can help local forecasters better predict flash flooding (heavy precipitation) that follows Florida heat waves.

Originally, we identified 18 north, 37 central, and 35 south precipitation events. Heavy and light precipitation events were originally defined as the top and bottom 10 events in each sector, respectively. However, we later combined the central and south sector events into a single central-south sector. This was justified by the similar synoptic-scale patterns observed throughout the analysis of the original central and south sectors (not shown), including all three precipitation ingredients. As such, the heavy and light composites in the central-south sector are composed of the top and bottom 20 precipitation events, respectively. Because the north sector only featured 18 total events, we used the top and bottom nine cases to create heavy and light composites, respectively. The north sector was retained as a separate entity because of the large differences in warm-season precipitation climatologies between the Florida Panhandle and Peninsula (Schwartz and Bosart 1979; Blanchard and Lopez 1985).

Table 1 shows precipitation statistics for heavy and light events. In both sectors, precipitation ranges exhibit reasonable separation between heavy and light events, although separation in the north sector is somewhat limited by its relatively small number of events. Median and mean amounts are quite similar between the two sectors (Table 1). Figure 4 shows composite mean precipitation for the heavy and light categories in each sector. In the north sector (Figs. 4a,b), both the heavy and light composites feature precipitation over much of Florida; much of the precipitation in the heavy composite (Fig. 4a) is located near KTLH and over adjacent Gulf waters. In contrast, almost all of the precipitation in the north sector light composite (Fig. 4b) is located south and east of the north sector. In the central-south heavy composite (Fig. 4c), precipitation is spread relatively evenly across the sector. In contrast, the centralsouth light composite features little to no precipitation across Florida (Fig. 4d).

In the next two sections, we use composites to analyze the synoptic-scale characteristics during both the heat wave and subsequent precipitation periods. For precipitation mechanisms, we utilize the Doswell et al. (1996) ingredients-based methodology (lift, moisture, instability) for flash flooding to compare responsible mechanisms for heavy and light events in each sector, as well as elucidate intersector differences. Mass field analyses presented in sections $4 \mathrm{~b}$ and $4 \mathrm{c}$ use monthly weighted composite means and anomalies, and the Student's $t$ test is used to evaluate the statistical significance of the anomalies at the $95 \%$ and $99 \%$ confidence intervals.

\section{b. Large-scale flow patterns}

To best discuss both the heat wave and subsequent precipitation period, heavy and light composites for each sector are displayed at $t=-48,-24,+24$, and $+48 \mathrm{~h}$, where $t=0 \mathrm{~h}$ is defined as the start of the $72-\mathrm{h}$ precipitation period. Henceforth, we use "heat wave period" to refer to $t=-48$ and $-24 \mathrm{~h}$ and "precipitation period" to refer to $t=+24$ and $+48 \mathrm{~h}$. Monthly weighted 


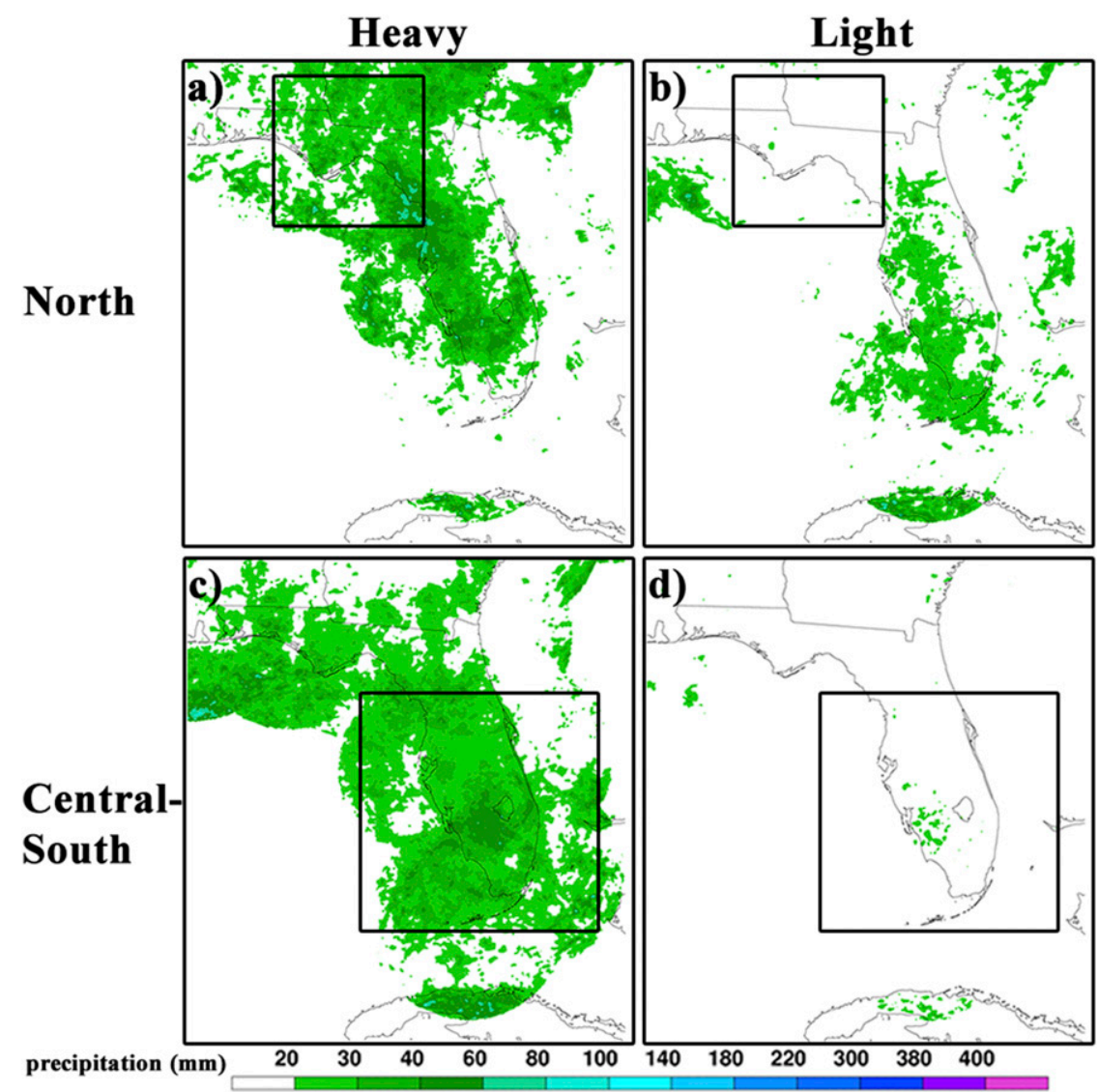

FIG. 4. NCEP stage IV 72-h composite mean precipitation (mm; shaded) for the three days following a heat wave for the (a),(c) heavy and (b),(d) light precipitation event categories in the (a),(b) north and (c),(d) central-south sectors. The black boxes in each panel outline the areas of each sector.

composite anomalies and means of $500-\mathrm{hPa}$ geopotential height are shown in Figs. 5 and 6 for the north and central-south sectors, respectively. In the north sector, the heat wave period during heavy and light events is characterized by an anomalous $500-\mathrm{hPa}$ ridge located over the central Gulf Coast (Figs. 5a-d). The anomalous ridge is statistically significant in both composites, but its areal extent is larger in heavy events. The heat wave period in the north sector is clearly characterized by a continental ridge, not the BermudaAzores high; this is discussed further with respect to the central-south sector results below.

Key differences between north heavy and light events develop by the precipitation period. In the heavy composite, the Gulf Coast ridge weakens slightly and retreats westward, as a positively tilted $500-\mathrm{hPa}$ trough becomes situated off the southeast U.S. coast (Figs. 5e,g). Negative $500-\mathrm{hPa}$ geopotential height anomalies in the base of the trough become statistically significant at the $95 \%$ confidence interval at $t=+48 \mathrm{~h}$ (Fig. $5 \mathrm{~g}$ ). In the light composite (Figs. 5f,h), the anomalous 500-hPa ridge retrogrades sooner and farther west, which allows a more amplified and progressive trough (and associated cold front) to move through northern Florida after the heat wave ends. The associated cold front in the light composite helps usher in cooler and, more importantly, drier air that contributes to smaller amounts of precipitation (section 4c).

The heavy and light composites in the central-south sector both feature statistically significant anomalous ridges over the Florida Peninsula during the heat wave period (Figs. 6a-d). As in the north sector results, this suggests favorable conditions for strong subsidence. However, there are subtle but important differences between the heavy and light composites. In heavy events, positive 500-hPa height anomalies stretch from the Great Lakes to the eastern Caribbean (Figs. 6a,c). This suggests that the anomalous ridge is of both continental and subtropical origin, especially considering the statistically significant positive geopotential height anomalies located over much of the northern Caribbean (Figs. 6a,c). The connection to the subtropical 

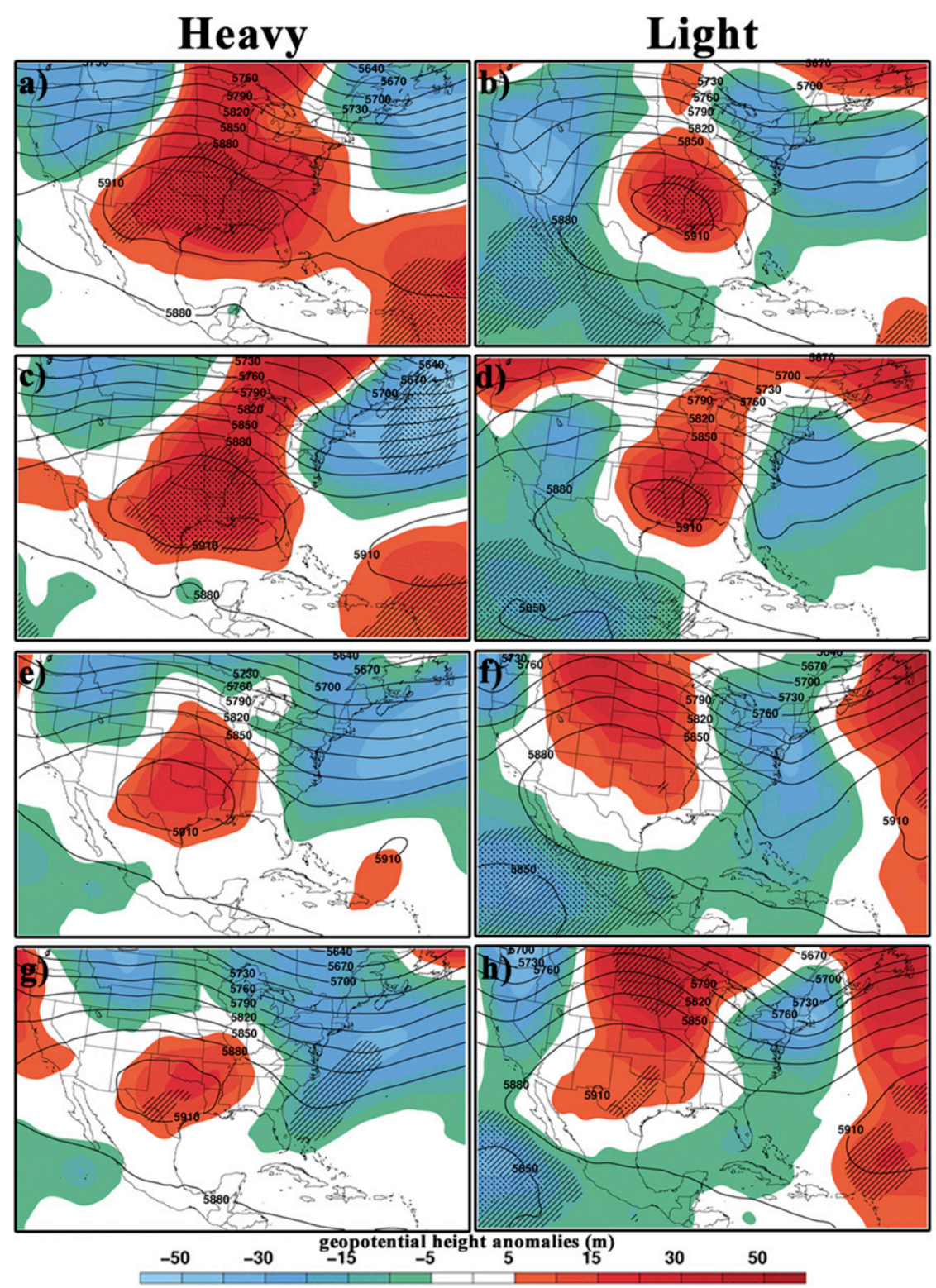

FIG. 5. For (a),(c),(e),(g) heavy and (b),(d),(f),(h) light precipitation events in the north sector: ERA-Interim 500-hPa geopotential height monthly weighted composite anomalies (m; shaded) and composite means ( $m$; solid black contours) at (a),(b) -48 , (c),(d) -24 , (e),(f) +24 , and $(\mathrm{g}),(\mathrm{h})+48 \mathrm{~h}$, where $0 \mathrm{~h}$ is $1200 \mathrm{UTC}$ on the last day of the heat wave. Grid points with statistically significant anomalies at the $95 \%$ and $99 \%$ confidence intervals according to the Student's $t$ test are hatched and dotted, respectively.

Bermuda-Azores high is an important finding in the context of climate change, as it is projected to intensify during the coming decades (He et al. 2017). In contrast, the ridge in the light composite is smaller in areal extent, and there are no statistically significant height anomalies over the Caribbean (Figs. 6b,d).

During the precipitation period, the central-south composite flow pattern over North America is more meridional in heavy (Figs. 6e,g) than in light events
(Figs. 6f,h). In the heavy composite, the anomalous ridge dissipates sooner, and an anticyclonic wave break occurs over the eastern Gulf of Mexico between $t=+24$ and $+48 \mathrm{~h}$ (Figs. 6e,g), allowing anomalously low geopotential heights to appear just off the southwest Florida coast by $t=+48 \mathrm{~h}$ (Fig. $6 \mathrm{~g}$ ). The anomalous troughing in heavy events helps to create an environment favorable for precipitation (section $4 \mathrm{c}$ ), while anomalous ridging remains over much of Florida during the light composite 

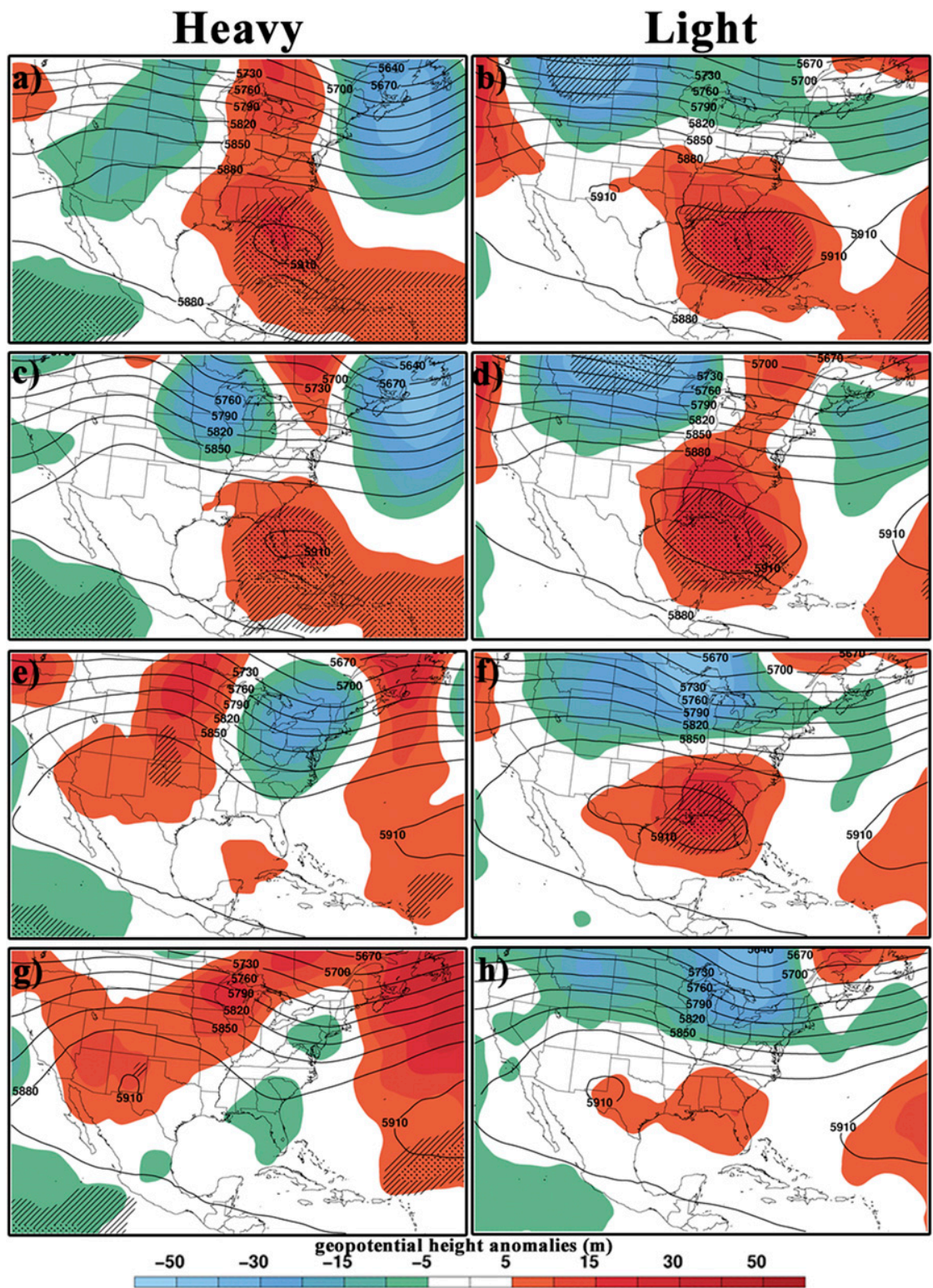

FIG. 6. As in Fig. 5, but for the central-south sector.

precipitation period (Figs. 6f,h). Overall, the post-heat wave light composite flow regime is characteristic of subsidence and less conducive to precipitation.

\section{c. Precipitation ingredients}

\section{1) Moisture}

To investigate the dynamic and thermodynamic mechanisms associated with precipitation events that follow heat waves, we used the Doswell et al. (1996) ingredients-based methodology for flash flooding. For the moisture ingredient, we produced composites of integrated water vapor (IWV), defined by Eq. (1):

$$
\mathrm{IWV}=\frac{1}{g \rho} \int_{\text {surface }}^{300 \mathrm{hPa}} q d p,
$$

where $g$ is the gravitational acceleration, $\rho$ is the density of liquid water, $q$ is specific humidity, and $p$ is pressure.

Figures 7 and 8 show composite IWV anomalies and mean sea level pressure (MSLP) for the north and central-south sectors, respectively. For the north sector Figs. 7a-d display no statistically significant IWV anomalies during the heat wave period for either heavy or light events. However, statistically significant positive IWV anomalies are observed over the north sector in the heavy composite during the precipitation period (Figs. 7e,g). 
In contrast, the light composite features no positive IWV anomalies at any time over the north sector. Furthermore, negative IWV anomalies (i.e., drier air) move into the north sector at $t=+24 \mathrm{~h}$ (Fig. 7f) and become statistically significant at $t=+48 \mathrm{~h}$ (Fig. 7h).

Composite MSLP patterns are also quite different between heavy and light events. In the heavy composite, a westward extension of the Bermuda-Azores high is observed throughout the entire evolution but particularly during the precipitation period (Figs. 7a,c,e,g). This helps transport moisture northward over the Gulf of Mexico, resulting in persistent positive IWV anomalies over the north sector. Meanwhile, a weak MSLP trough, associated with the positively tilted 500-hPa trough seen in Fig. 5, is observed over the mid-Atlantic coast. The MSLP patterns at $t=+24$ and $+48 \mathrm{~h}$ (Figs. 7e,g) are broadly suggestive of a quasi-stationary boundary located over the north sector, which is conducive to precipitation. In contrast, the light composite features a stronger continental MSLP anticyclone to the north, which helps advect drier air into the region after the heat wave ends (Figs. 7b,d,f,h).

The central-south sector IWV/MSLP composites are like the north sector results in that no statistically significant IWV anomalies are observed over the sector during the heat wave period (Figs. 8a-d). Important differences again become evident by the precipitation period. In the heavy composite, statistically significant positive IWV anomalies are located across the central-south sector at $t=+24$ and $+48 \mathrm{~h}$ (Figs. 8e,g), especially in the western half of the sector. This is associated with a westward extension of the Bermuda-Azores high and an MSLP pattern conducive to a quasistationary boundary being located over the Florida Peninsula, especially during the precipitation period (Figs. 8a,c,e,g).

In the central-south light composite, the MSLP anticyclone over the Appalachians is centered farther south than in the heavy composite (Figs. 8b,d,f), allowing weak negative IWV anomalies to move into central Florida by $t=+24 \mathrm{~h}$ (Fig. 8f). In addition, the Bermuda-Azores high is located farther offshore in the light composite, which is less conducive to the development of a quasi-stationary boundary over the Florida Peninsula. Although warm-season synopticscale pressure gradients over Florida are typically weak, subtle differences are important, especially in terms of precipitation ingredients; this is emphasized by the differences between heavy and light events.

A key difference between the north and central-south composites is observed for light events. In the north light composite, statistically significant negative IWV anomalies move into the north sector during the precipitation period (Fig. 7), while negative IWV anomalies in the central-south light events during the same period are weak to nonexistent (Fig. 8). This suggests that north light events are predominantly influenced by advection of drier air into the region, while central-south light events are most affected by persistent subsidence. In other words, the prolonged ridging (Fig. 6) and associated subsidence in central-south light events likely acts to inhibit precipitation after the heat wave ends; we discuss this further below.

\section{2) LIFT}

Banacos and Schultz (2005) showed that moisture flux convergence (MFC) is proportional to horizontal mass convergence. Through the principle of mass continuity, lower-tropospheric MFC is therefore indicative of ascent. We calculated 1000-850-hPa layer-averaged MFC composite means and anomalies using integrated vapor transport (IVT; Moore et al. 2012):

$$
\mathrm{IVT}=\frac{1}{g} \int_{1000 \mathrm{hPa}}^{850 \mathrm{hPa}} q \mathbf{v}_{h} d p,
$$

where $g$ is the gravitational acceleration, $q$ is specific humidity, $\mathbf{v}_{h}$ is the horizontal wind velocity, and $p$ is pressure.

MFC was then calculated using Eq. (3):

$$
\mathrm{MFC}=-\nabla \cdot(\mathrm{IVT})
$$

The 1000-850-hPa layer was chosen because of the relationship between lower-tropospheric MFC and ascent, which is an ingredient for heavy precipitation. Other lower-tropospheric layers (e.g., 1000-700 hPa) were tested, but the MFC signal was strongest near the surface. Because MFC is a negative quantity and anomalies are plotted in Figs. 9 and 10, to avoid confusion, we refer to strong (weak) MFC as a large (small) MFC anomaly. In general, strong positive anomalies indicate moisture flux divergence, which is associated with descent.

In the north sector, the heat wave period is characterized by weak MFC over the region with no statistically significant anomalies (Figs. 9a-d). By the heavy composite precipitation period, a statistically significant large MFC anomaly progressively builds over the southern portion of the north sector (Figs. 9e,g). Concurrently, northward IVT is present in the eastern Gulf of Mexico, which corresponds to the MSLP and IWV patterns in Fig. 7. In contrast, the light composite features anomalously weak MFC over the north sector throughout the precipitation period (Figs. 9f,h). These findings support the assertion of stronger ascent over the north sector during heavy events. 
Heavy
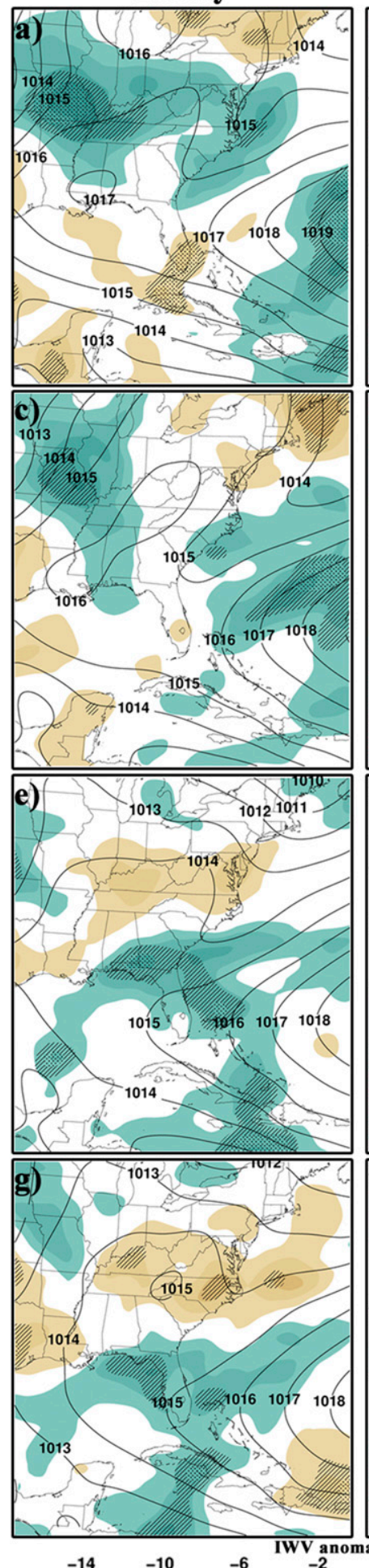

\section{Light}
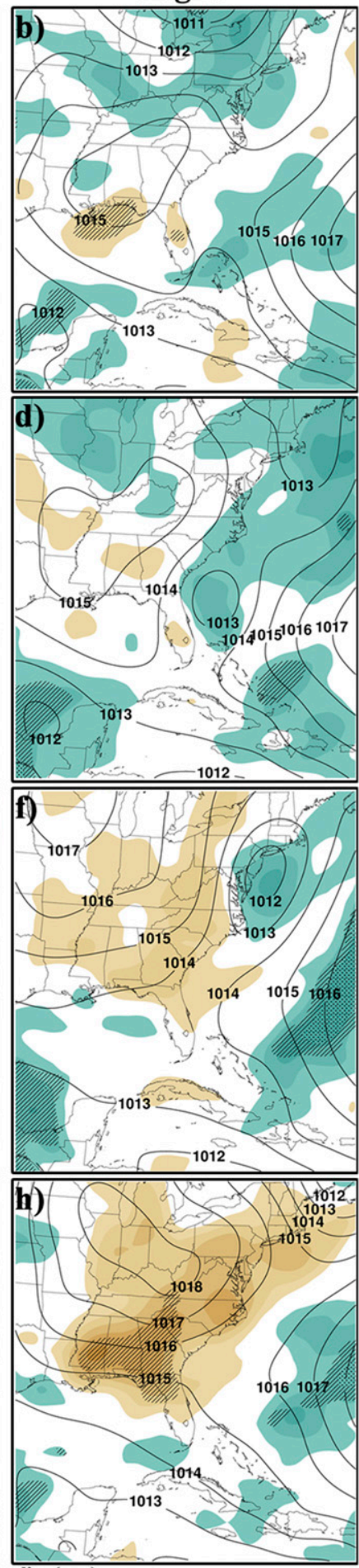

FIG. 7. For (a),(c),(e),(g) heavy and (b),(d),(f),(h) light precipitation events in the north sector: ERA-Interim IWV monthly weighted composite anomalies (mm; shaded) and MSLP (hPa; solid black contours) at (a),(b) $-48,(\mathrm{c}),(\mathrm{d})-24,(\mathrm{e}),(\mathrm{f})+24$, and (g),(h) $+48 \mathrm{~h}$. Grid points with statistically significant anomalies at the $95 \%$ and $99 \%$ confidence intervals according to the Student's $t$ test are hatched and dotted, respectively. 


\section{Heavy}
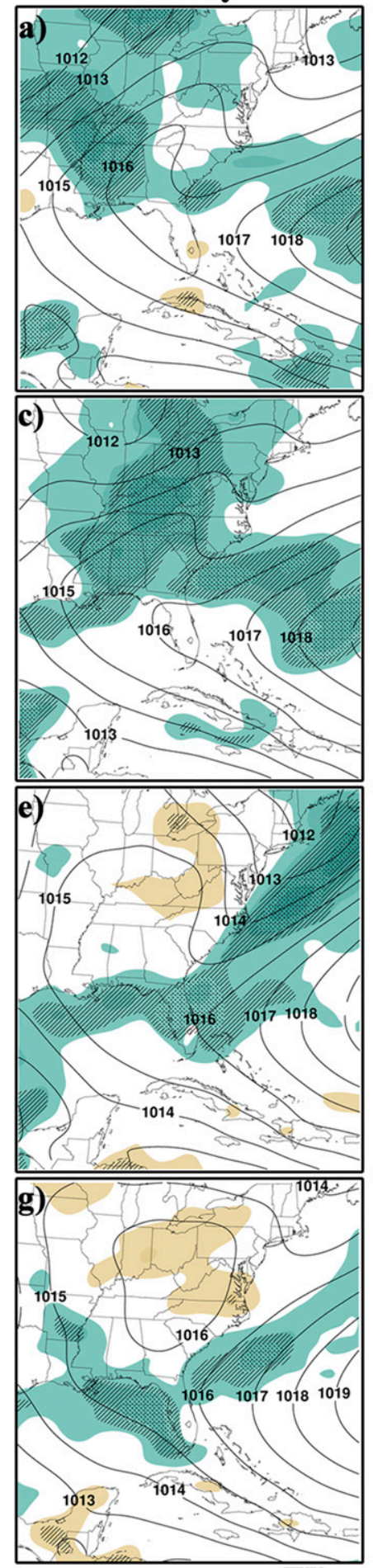

IWV anomalies

\section{Light}
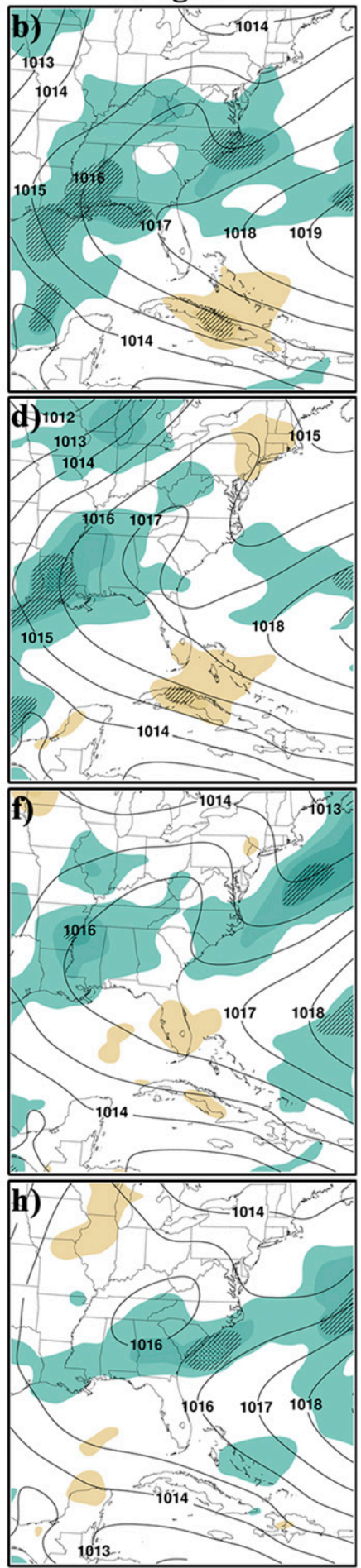

FIG. 8. As in Fig. 7, but for the central-south sector. 

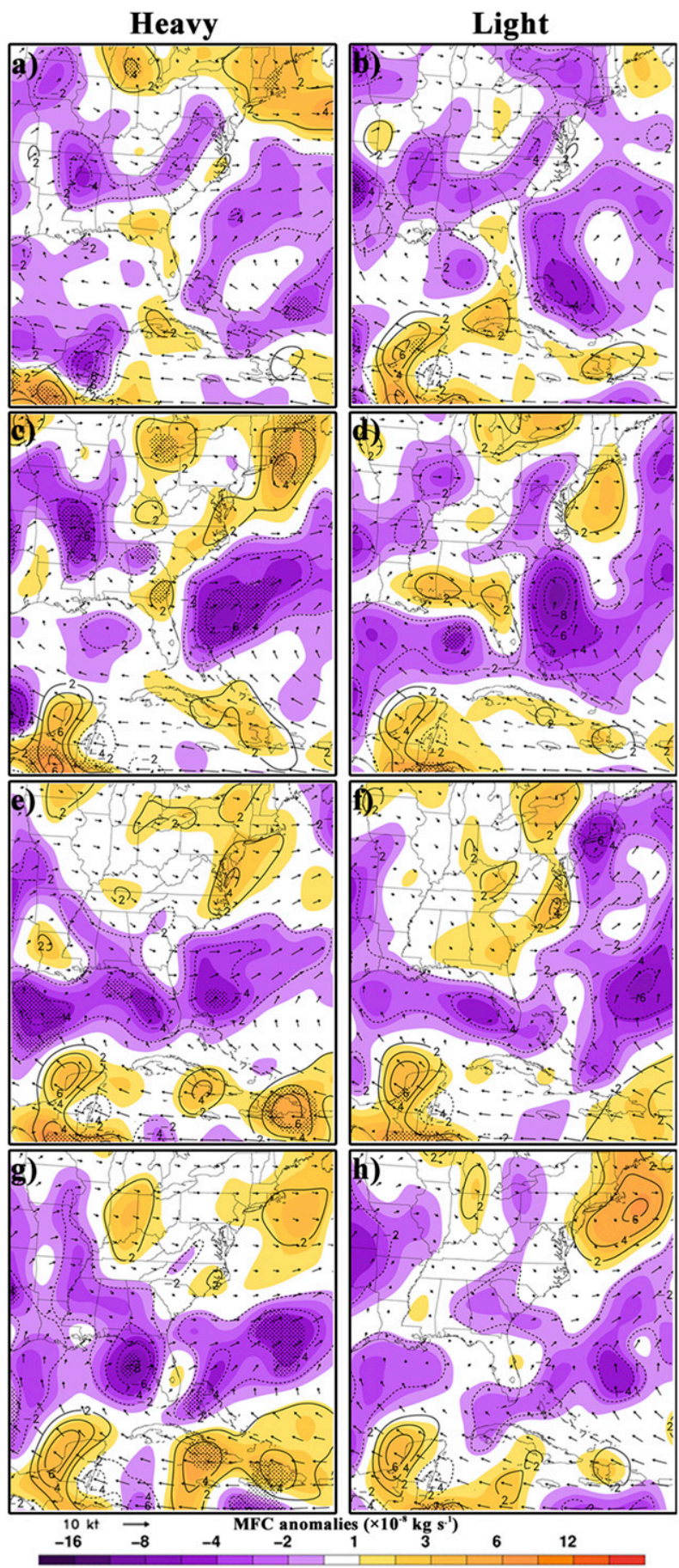

FIG. 9. For (a),(c),(e),(g) heavy and (b),(d),(f),(h) light precipitation events in the north sector: ERA-Interim 1000-850-hPa layer-averaged MFC monthly weighted composite anomalies $\left(\times 10^{-8} \mathrm{~kg} \mathrm{~s}^{-1}\right.$; shaded $)$, composite means $\left(\times 10^{-8} \mathrm{~kg} \mathrm{~s}^{-1}\right.$; solid black contours for moisture flux divergence; dashed black contours for MFC), and IVT $\left(\mathrm{kg} \mathrm{m}^{-1} \mathrm{~s}^{-1}\right.$; vectors) at (a),(b) -48 , (c), (d) -24 , (e),(f) +24 , and (g),(h) $+48 \mathrm{~h}$. Grid points with statistically significant anomalies at the $95 \%$ and $99 \%$ confidence intervals according to the Student's $t$ test are hatched and dotted, respectively.
In the central-south sector, statistically significant small MFC anomalies are present over most of the Florida Peninsula in both the heavy and light composites (Figs. 10a-d), suggesting descent. During the precipitation period, however, there are substantial differences between heavy and light events. In the heavy composite, a large MFC anomaly progressively builds over the western portion of the central-south sector (Figs. 10e,g). IVT is primarily northwestward on the fringe of the Bermuda-Azores high westward extension (Fig. 8) and then northward along the Florida Gulf Coast (Figs. 10e,g). In the light composite, anomalously small MFC is located over the Florida Peninsula throughout the precipitation period (Figs. 10f,h), although the anomalies are not statistically significant. Less ascent in the light composite precipitation period, especially compared to the heavy composite, is consistent with the longer-duration ridging (Fig. 6) that promotes subsidence. In addition, the weaker IVT in the light composite, particularly over the western half of the central-south sector, corresponds to the lesser westward extent of the Bermuda-Azores high (Fig. 8).

Overall, the heat wave periods in both sectors are characterized by anomalously small MFC, although the anomalies are only statistically significant in the centralsouth sector. During the precipitation period, heavy events in both sectors feature statistically significant large MFC, but the differences between the heavy and light composites are starker in the central-south sector. These observations support the idea that moisture differences are more important during the north sector precipitation period, while ascent differences are more prominent in the central-south sector.

To investigate other ascent-forcing mechanisms, we examined jet streak dynamics, upper-tropospheric vorticity advection, and lower-tropospheric temperature advection (not shown). No coherent composite signals were found in any of these fields, largely because most baroclinicity and associated midlatitude synoptic-scale ascent-forcing mechanisms are located far north of Florida during summer. We therefore surmise that surface convergence (and associated MFC) is the primary ascent-forcing mechanism during the warm season in Florida, which is consistent with past research (e.g., Gentry and Moore 1954; Estoque 1962; Schwartz and Bosart 1979).

\section{3) INSTABILITY AND THERMODYNAMIC ENVIRONMENT}

Area-averaged composite soundings were produced for each sector to investigate instability and other thermodynamic properties. For each composite sounding, we calculated most unstable convective available potential 


\section{Heavy}
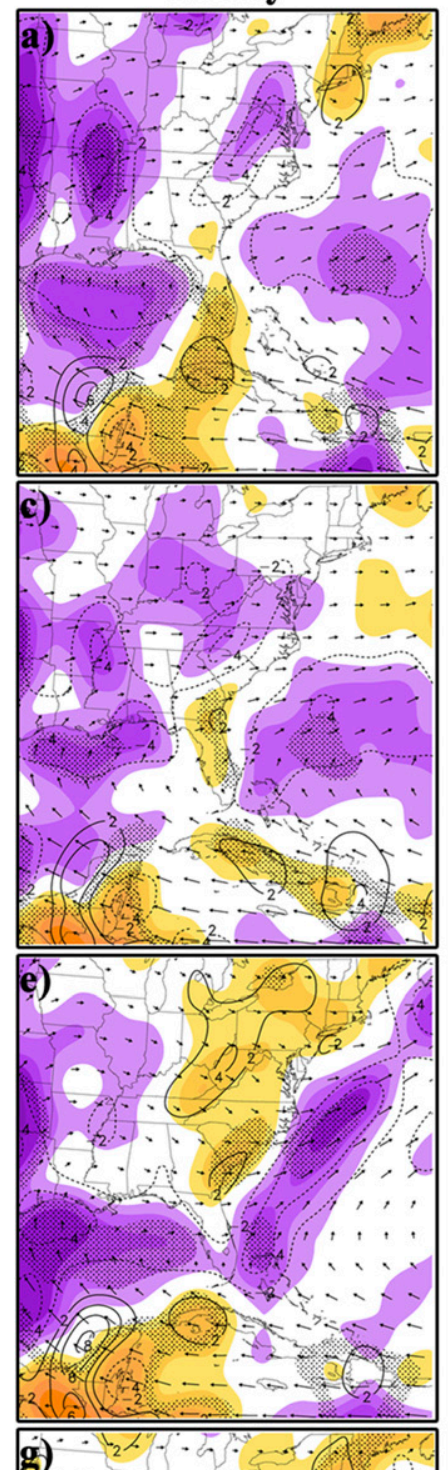

g)

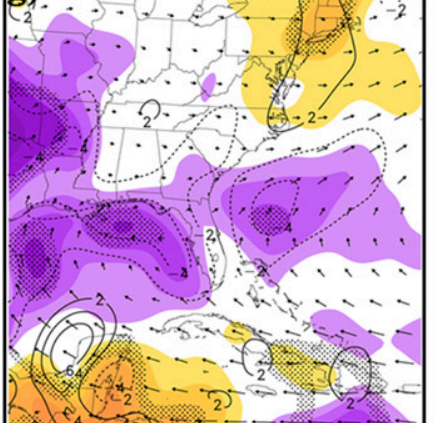

\section{Light}
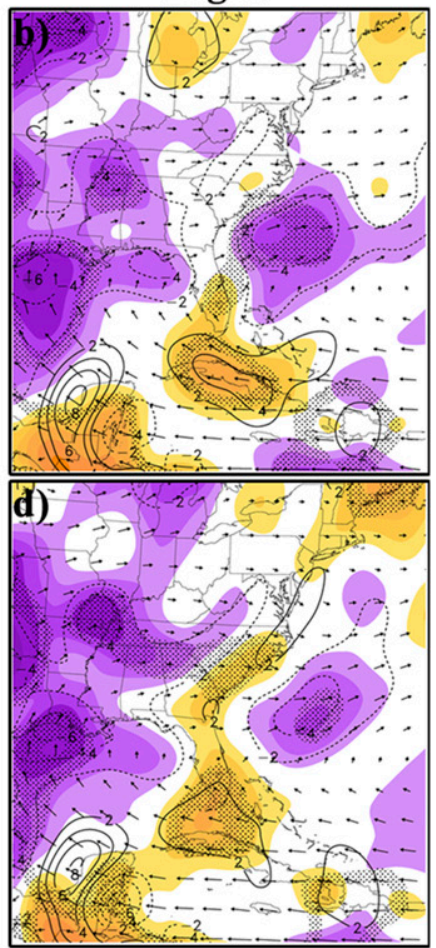

d)
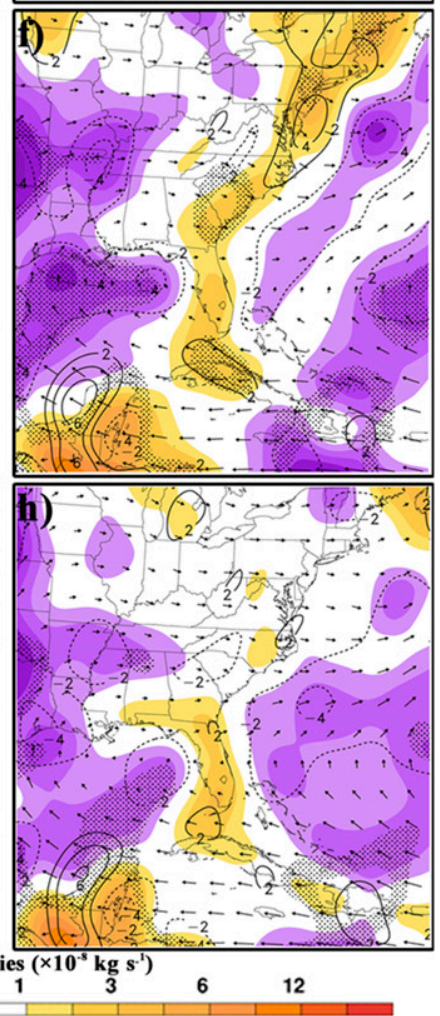

FIG. 10. As in Fig. 9, but for the central-south sector. 
TABLE 2. Area-averaged thermodynamic variables derived from composite soundings for the heavy and light composites in the north and central-south sectors. Listed are MUCAPE; $\left(\mathrm{J} \mathrm{kg}^{-1}\right)$, IWV $(\mathrm{mm})$, and $\mathrm{KI}\left({ }^{\circ} \mathrm{C}\right)$ at the composite times of $t=-48,-24,0,+24$, and $+48 \mathrm{~h}$.

\begin{tabular}{|c|c|c|c|c|}
\hline Sector (category) & Composite time (h) & MUCAPE $\left(\mathrm{J} \mathrm{kg}^{-1}\right)$ & IWV (mm) & $\mathrm{KI}\left({ }^{\circ} \mathrm{C}\right)$ \\
\hline \multirow[t]{5}{*}{ North (heavy) } & -48 & 1597 & 44.5 & 29 \\
\hline & -24 & 1604 & 45.0 & 31 \\
\hline & 0 & 2167 & 47.8 & 32 \\
\hline & 24 & 2784 & 49.8 & 34 \\
\hline & 48 & 1372 & 48.8 & 33 \\
\hline \multirow[t]{5}{*}{ North (light) } & -48 & 1621 & 42.4 & 28 \\
\hline & -24 & 1645 & 45.0 & 30 \\
\hline & 0 & 1573 & 44.0 & 30 \\
\hline & 24 & 732 & 42.7 & 29 \\
\hline & 48 & 626 & 37.8 & 24 \\
\hline \multirow[t]{5}{*}{ Central-south (heavy) } & -48 & 1653 & 43.2 & 28 \\
\hline & -24 & 1846 & 43.7 & 28 \\
\hline & 0 & 1934 & 44.7 & 29 \\
\hline & 24 & 1546 & 46.7 & 32 \\
\hline & 48 & 1419 & 46.2 & 31 \\
\hline \multirow[t]{5}{*}{ Central-south (light) } & -48 & 1695 & 45.2 & 29 \\
\hline & -24 & 1760 & 43.7 & 27 \\
\hline & 0 & 1628 & 43.2 & 28 \\
\hline & 24 & 1458 & 42.2 & 27 \\
\hline & 48 & 1319 & 44.2 & 29 \\
\hline
\end{tabular}

energy (MUCAPE), IWV, and $K$ index (KI), shown in Table 2. KI is a useful tool to evaluate the likelihood of thunderstorms in regions marked by weak synopticscale flow, such as Florida in summer (Fuelberg and Biggar 1994). KI is defined by Eq. (4):

$$
\mathrm{KI}=\left(T_{850}-T_{500}\right)+T_{d 850}-T_{\mathrm{dd} 700},
$$

where $T$ is temperature $\left({ }^{\circ} \mathrm{C}\right), T_{d}$ is dewpoint temperature $\left({ }^{\circ} \mathrm{C}\right), T_{\mathrm{dd}}$ is dewpoint depression $\left({ }^{\circ} \mathrm{C}\right)$, and the numeric subscripts refer to pressure level (hPa). Fuelberg and Biggar (1994) used KI to analyze Florida warm-season thunderstorm ingredients and stated that $\mathrm{KI}>28^{\circ} \mathrm{C}$ indicates a high likelihood of thunderstorms. We use MUCAPE to assess the overall instability in our composite soundings, while IWV and KI are used to facilitate a more complete discussion of thermodynamic ingredients associated with heavy rainfall.

In the north sector, heavy and light events have comparable MUCAPE, IWV, and KI values during the heat wave period (Table 2). However, starting at $t=0 \mathrm{~h}$ and continuing through the precipitation period, heavy events feature much larger MUCAPE, IWV, and KI (Table 2). Strong instability exists in heavy events, especially at $t=0$ and $t=+24 \mathrm{~h}$ when MUCAPE is $>2000 \mathrm{~J} \mathrm{~kg}^{-1}$. In the light events, MUCAPE values of $<1000 \mathrm{~J} \mathrm{~kg}^{-1}$ at $t=+24$ and $t=+48 \mathrm{~h}$ are not all that conducive to convection. The differences in IWV and KI during the precipitation period exemplify the large moisture differences between north sector heavy and light events. Overall, the post-heat wave thermodynamic environment in the heavy composite is much more conducive to precipitation.

In the central-south sector, MUCAPE, IWV, and KI are relatively similar between heavy and light events during the heat wave period (Table 2). For the precipitation period, heavy events feature larger values of all three indices (Table 2), but the differences between heavy and light events are not nearly as stark as they are in the north sector. To quantify this, we computed statistical significance according to the Student's $t$ test for each variable (MUCAPE, IWV, KI) in Table 2. We found that the differences between the north heavy and light events are generally statistically significant at the $90 \%$ confidence interval ( $p$ values of $0.09,0.02$, and 0.035 for MUCAPE, IWV, and KI, respectively), while differences between the central heavy and light events ( $p$ values of $0.41,0.19$, and 0.13 , respectively) are not. These results support our assertion that the most important differences between heavy and light events in the central-south sector are related to ascent (dynamics), while the predominant differences in the north sector are found in moisture (thermodynamics).

\section{Conclusions and future work}

We established a climatology and trend analysis of summer heat waves at seven major airports across 
Florida from 1950 to 2016, using the 95th percentiles of daily maximum, minimum, and mean temperatures. Our analysis shows that heat waves exhibit statistically significant increases in frequency and duration at most locations, especially for mean and minimum temperature events. KTLH is the only station where frequency and duration increases are statistically significant for all three temperature variables, suggesting the importance of the climatological sea breezes in mitigating maximum temperature heat waves in the Florida Peninsula.

The most pronounced combined frequency and duration increases in mean and minimum temperature events are found at KTLH, KTPA, KMIA, and KEYW. The largest overall increases are found at KTPA, with alarming minimum and mean heat wave frequency $\left(+0.346\right.$ and +0.321 events decade $\left.{ }^{-1}\right)$ and duration $\left(+0.691\right.$ and +0.510 days decade $\left.{ }^{-1}\right)$ increases. While increased urbanization cannot be discounted as a factor in heat wave frequency and duration changes at stations such as KTPA and KMIA (Keellings and Waylen 2014), heat wave increases at KEYW (where population has remained nearly constant since the 1960s) suggest that it plays a supporting role. Rapid increases in population and urbanization make the increases at KTPA more concerning, especially in terms of older populations that may lack air conditioning (Florida Department of Health 2015). Increases in the frequency and duration of minimum temperature heat waves throughout Florida are also quite concerning given the negative health impacts of nighttime heat (Florida Department of Health 2015; Mora et al. 2017; Nissan et al. 2017).

Synoptic-scale composites show that the heat wave periods in both of our geographical sectors are characterized by anomalous midtropospheric ridging and subsidence. However, north events are dominated by anomalous continental ridging, while the anomalous ridging in central-south heat waves emanates from both continental and maritime subtropical sources. The Bermuda-Azores high is particularly prominent in the central-south heavy composite, suggesting it is an important precursor to heavy precipitation events in the peninsula.

Using an ingredients-based analysis (lift, moisture, instability) for flash flooding, we examined composites during the 3-day period that followed heat waves. Rainfall events that followed heat waves were partitioned into heavy and light categories to investigate the responsible mechanisms for precipitation. Heavy rainfall events in both geographical sectors are characterized by anomalously large MFC (ascent), statistically significant positive IWV anomalies, and large instability. In contrast, light events feature anomalously small
MFC (descent) and generally smaller amounts of moisture and instability.

Important intersector differences were also found. The differences between heavy and light events in the north sector appear to be dominated by much drier air in light events, associated with a progressive continental anticyclone. However, in central-south events, the key difference between heavy and light events is vertical motion, where prolonged midtropospheric ridging during the post-heat wave period promotes subsidence despite relatively similar moisture and instability values.

The mechanisms discussed here are important for forecasters trying to predict rainfall amounts during post-heat wave periods and have important consequences in the context of climate change. To the latter point, R19 used a subset (2000-13) of our heat waves to perform high-resolution numerical model experiments using a pseudo-global warming (PGW) approach. PGW incorporates projected thermodynamic (i.e., heat and moisture) changes but does not alter atmospheric dynamics (i.e., ascent-forcing mechanisms). Through the PGW approach, R19 found that heavy precipitation events in the three days following a Florida heat wave will increase in frequency and intensity, particularly in the peninsula where two climatological sea breezes generally promote ascent. As such, moisture changes will be crucial, as water vapor concentration near Florida is projected to increase in a warming world, particularly over the warmer SSTs of the Gulf of Mexico (e.g., Little et al. 2015; Taylor and Clarke 2018). However, future dynamic changes should not be entirely ignored. As R19 pointed out, the projected expansion of the Hadley cell may result in enhanced subsidence over portions of the subtropics, which could potentially decrease precipitation amounts in light events (as seen in our central-south results).

Specific future work should include an evaluation as to whether precipitation events that follow summer heat waves in Florida are more intense than precipitation events following a non-heat wave period. In addition, an analysis of precipitation events for each individual temperature variable (i.e., minimum temperature) should be performed to investigate whether certain types of heat waves (i.e., daytime only, nighttime only) are more likely to be followed by heavy precipitation events. Similar heat wave and precipitation analyses should also be conducted for other seasons; while cold-season heat waves are not an issue in most midlatitude locations, they can result in very warm nighttime temperatures in Florida, which in turn can impact human health. Finally, analyzing Florida summer heat waves using a heat wave definition that incorporates both temperature and moisture would 
be interesting to compare to this study and R19. As Schoof et al. (2017) and Li et al. (2018) found, humidity is a key factor in heat wave impacts, especially in subtropical maritime climates.

From a climate change standpoint and to further the results of R19, the role of SSTs in facilitating heat waves and airmass modification needs to be quantified for locations such as KTPA and KEYW, which are surrounded by warm water. Specifically, high-resolution numerical model sensitivity experiments should be conducted to determine whether projected increases in heat wave and heavy precipitation frequency are directly related to warmer SSTs over adjacent waters.

Acknowledgments. This study was primarily supported by an Embry-Riddle Aeronautical University (ERAU) internal research grant. Raghavendra acknowledges funding support from the National Science Foundation (NSF AGS-1535426). The authors would also like to thank the ERAU IGNITE program for providing funding for related conference presentations. We appreciate the efforts of Dr. Eyad Atallah of McGill University to provide feedback on the ingredients-based precipitation analysis. Finally, we are indebted to the three anonymous peer reviewers and editor for their insightful comments toward earlier versions of this manuscript.

\section{REFERENCES}

American Meteorological Society, 2018: Heat wave. Glossary of Meteorology, http://glossary.ametsoc.org/wiki/Heat_wave.

Banacos, P. C., and D. M. Schultz, 2005: The use of moisture flux convergence in forecasting convective initiation: Historical and operational perspectives. Wea. Forecasting, 20, 351-366, https://doi.org/10.1175/WAF858.1.

Blanchard, D. O., and R. E. Lopez, 1985: Spatial patterns of convection in south Florida. Mon. Wea. Rev., 113, 1282-1298, https://doi.org/10.1175/1520-0493(1985)113<1282: SPOCIS $>2.0 . \mathrm{CO} ; 2$.

Burpee, R. W., and L. N. Lahiff, 1984: Area-average rainfall variations on sea-breeze days in south Florida. Mon. Wea. Rev., 112, 520-534, https://doi.org/10.1175/1520-0493(1984)112<0520: AARVOS $>2.0 . \mathrm{CO} ; 2$.

Coumou, D., and S. Rahmstorf, 2012: A decade of weather extremes. Nat. Climate Change, 2, 491-496, https://doi.org/ 10.1038/nclimate1452.

Dai, A., R. M. Rasmussen, C. Liu, K. Ikeda, and A. F. Prein, 2019: A new mechanism for warm-season precipitation response to global warming based on convection-permitting simulations. Climate Dyn., https://doi.org/10.1007/s00382-017-3787-6, in press.

Dee, D. P., and Coauthors, 2011: The ERA-Interim reanalysis: Configuration and performance of the data assimilation system. Quart. J. Roy. Meteor. Soc., 137, 553-597, https://doi.org/ 10.1002/qj.828.

DeGaetano, A. T., W. Noon, and K. L. Eggleston, 2015: Efficient access to climate products using ACIS web services. Bull. Amer. Meteor. Soc., 96, 173-180, https://doi.org/10.1175/ BAMS-D-13-00032.1.
Diffenbaugh, N. S., and M. Ashfaq, 2010: Intensification of hot extremes in the United States. Geophys. Res. Lett., 37, L15701, https://doi.org/10.1029/2010GL043888.

Doswell, C. A., III, H. E. Brooks, and R. A. Maddox, 1996: Flash flood forecasting: An ingredients-based methodology. Wea. Forecasting, 11, 560-581, https://doi.org/10.1175/1520-0434(1996) $011<0560$ :FFFAIB $>2.0 . \mathrm{CO} ; 2$.

Estoque, M. A., 1962: The sea breeze as a function of the prevailing synoptic situation. J. Atmos. Sci., 19, 244-250, https://doi.org/ 10.1175/1520-0469(1962)019<0244:TSBAAF>2.0.CO;2.

Fischer, E. M., and R. Knutti, 2015: Anthropogenic contribution to global occurrence of heavy-precipitation and high-temperature extremes. Nat. Climate Change, 5, 560-564, https://doi.org/ 10.1038/nclimate2617.

Florida Department of Health, 2015: Health effects of summer heat in Florida. Florida Dept. of Health Rep., 24 pp., http:// www.floridahealth.gov/environmental-health/climate-andhealth/_documents/heat-profile.pdf.

Fuelberg, H. E., and D. G. Biggar, 1994: The preconvective environment of summer thunderstorms over the Florida Panhandle. Wea. Forecasting, 9, 316-326, https://doi.org/10.1175/15200434(1994)009<0316:TPEOST > 2.0.CO;2.

Gentry, R. C., and P. L. Moore, 1954: Relation of local and general wind interaction near the sea coast to time and location of airmass showers. J. Meteor., 11, 507-511, https://doi.org/10.1175/ 1520-0469(1954)011<0507:ROLAGW>2.0.CO;2.

Greene, S., L. Kalkstein, D. Mills, and J. Samenow, 2011: An examination of climate change on extreme heat events and climate-mortality relationships in large U.S. cities. Wea. Climate Soc., 3, 281-292, https://doi.org/10.1175/WCAS-D-11-00055.1.

Guirguis, K., A. Gershunova, D. R. Cayan, and D. W. Pierce, 2018: Heat wave probability in the changing climate of the southwest U.S. Climate Dyn., 50, 3853-3864, https://doi.org/10.1007/ s00382-017-3850-3.

He, C., B. Wu, L. Zou, and T. Zhou, 2017: Responses of the summertime subtropical anticyclones to global warming. J. Climate, 30, 6465-6479, https://doi.org/10.1175/JCLI-D16-0529.1.

Herrera-Estrada, J. E., and J. Sheffield, 2017: Uncertainties in future projections of summer droughts and heat waves over the contiguous United States. J. Climate, 30, 6225-6246, https:// doi.org/10.1175/JCLI-D-16-0491.1.

IPCC, 2013: Summary for policymakers. Climate Change 2013: The Physical Science Basis, T. F. Stocker et al., Eds., Cambridge University Press, 1-30, https://doi.org/10.1017/ CBO9781107415324.004.

Keellings, D., and P. Waylen, 2014: Increased risk of heat waves in Florida: Characterizing changes in bivariate heat wave risk using extreme value analysis. Appl. Geogr., 46, 90-97, https:// doi.org/10.1016/j.apgeog.2013.11.008.

, and - 2015: Investigating teleconnection drivers of bivariate heat waves in Florida using extreme value analysis. Climate Dyn., 44, 3383-3391, https://doi.org/10.1007/s00382014-2345-8.

Koch, S., M. DesJardins, and P. Kocin, 1983: An interactive Barnes objective map analysis scheme for use with satellite and conventional data. J. Climate Appl. Meteor., 22, 1487-1503, https://doi.org/10.1175/1520-0450(1983)022<1487: AIBOMA $>2.0 . \mathrm{CO} ; 2$.

Kunkel, K. E., T. R. Karl, D. R. Easterling, K. Redmond, J. Young, X. Yin, and P. Hennon, 2013: Probable maximum precipitation and climate change. Geophys. Res. Lett., 40, 1402-1408, https:// doi.org/10.1002/grl.50334. 
Li, J., Y. D. Chen, T. Y. Gan, and N.-C. Lau, 2018: Elevated increased in human-perceived temperature under climate warming. Nat. Climate Change, 8, 43-47, https://doi.org/10.1038/ s41558-017-0036-2.

Lin, Y., and K. E. Mitchell, 2005: The NCEP stage II/IV hourly precipitation analyses: Development and applications. 19th Conf. on Hydrology, San Diego, CA, Amer. Meteor. Soc., 1.2, http://ams.confex.com/ams/pdfpapers/83847.pdf.

Little, C. M., R. M. Horton, R. E. Kopp, M. Oppenheimer, G. A. Vecchi, and G. Villarini, 2015: Joint projections of U.S. East Coast sea level and storm surge. Nat. Climate Change, 5, 11141120, https://doi.org/10.1038/nclimate2801.

Liu, C., and Coauthors, 2017: Continental-scale convectionpermitting modeling of the current and future climate of North America. Climate Dyn., 49, 71-95, https://doi.org/10.1007/ s00382-016-3327-9.

Meehl, G. A., C. Tebaldi, G. Walton, D. Easterling, and L. McDaniel, 2009: Relative increase of record high maximum temperatures compared to record low minimum temperatures in the U.S. Geophys. Res. Lett., 36, L23701, https://doi.org/10.1029/ 2009GL040736.

__ J. M. Arblaster, and G. Branstator, 2012: Mechanisms contributing to the warming hole and the consequent U.S. east-west differential of heat extremes. J. Climate, 25, 63946408, https://doi.org/10.1175/JCLI-D-11-00655.1.

Moore, B. J., P. J. Neiman, F. M. Ralph, and F. E. Barthold, 2012: Physical processes associated with heavy flooding rainfall in Nashville, Tennessee, and vicinity during 1-2 May 2010: The role of an atmospheric river and mesoscale convective systems. Mon. Wea. Rev., 140, 358-378, https://doi.org/10.1175/ MWR-D-11-00126.1.

Mora, C., and Coauthors, 2017: Global risk of deadly heat. Nat. Climate Change, 7, 501-506, https://doi.org/10.1038/nclimate3322.

Nissan, H., K. Burkart, E. C. de Perez, M. Van Aalst, and S. Mason, 2017: Defining and predicting heat waves in Bangladesh. J. Appl. Meteor. Climatol., 56, 2653-2670, https://doi.org/10.1175/ JAMC-D-17-0035.1.

Ortiz, L. E., and J. E. Gonzalez, 2018: New York City impacts on a regional heat wave. J. Appl. Meteor. Climatol., 57, 837-851, https://doi.org/10.1175/JAMC-D-17-0125.1.

Partridge, T. F., J. M. Winter, E. C. Osterberg, D. W. Hyndman, A. D. Kendall, and F. J. Magilligan, 2018: Spatially distinct seasonal patterns and forcings of the U.S. warming hole. Geophys. Res. Lett., 45, 2055-2063, https://doi.org/10.1002/ 2017 GL076463.
Perkins, S. E., 2015: A review on the scientific understanding of heatwaves-- Their measurement, driving mechanisms, and changes at the global scale. Atmos. Res., 164-165, 242-267, https://doi.org/10.1016/j.atmosres.2015.05.014.

- L. V. Alexander, and J. R. Nairn, 2012: Increasing frequency, intensity, and duration of observed global heat waves and warm spells. Geophys. Res. Lett., 39, L20714, https://doi.org/ 10.1029/2012GL053361.

Prein, A. F., R. M. Rasmussen, K. Ikeda, C. Liu, M. P. Clark, and G. J. Holland, 2017: The future intensification of hourly precipitation extremes. Nat. Climate Change, 7, 48-52, https:// doi.org/10.1038/nclimate3168.

Raghavendra, A., A. Dai, S. M. Milrad, and S. R. Cloutier-Bisbee, 2019: Floridian heat waves and extreme precipitation: Future climate projections. Climate Dyn., https://doi.org/10.1007/ s00382-018-4148-9, in press.

Ramamurthy, P., and E. Bou-Zeid, 2017: Heatwaves and urban heat islands: A comparative analysis of multiple cities. J. Geophys. Res. Atmos., 122, 168-178, https://doi.org/10.1002/2016JD025357.

Riahi, K., and Coauthors, 2011: RCP 8.5-A scenario of comparatively high greenhouse gas emissions. Climatic Change, 109, 33-57, https://doi.org/10.1007/s10584-011-0149-y.

Rogers, J. C., 2013: The 20th century cooling trend over the southeastern United States. Climate Dyn., 40, 341-352, https://doi.org/ 10.1007/s00382-012-1437-6.

Schoof, J. T., T. W. Ford, and S. C. Pryor, 2017: Recent changes in U.S. regional heat wave characteristics in observations and reanalyses. J. Appl. Meteor. Climatol., 56, 2621-2636, https:// doi.org/10.1175/JAMC-D-16-0393.1.

Schwartz, B. E., and L. F. Bosart, 1979: The diurnal variability of Florida rainfall. Mon. Wea. Rev., 107, 1535-1545, https://doi.org/ 10.1175/1520-0493(1979)107<1535:TDVOFR >2.0.CO;2.

Smith, T. T., B. F. Zaitchik, and J. M. Gohlke, 2013: Heat waves in the United States: Definitions, patterns, and trends. Climatic Change, 118, 811-825, https://doi.org/10.1007/s10584-0120659-2.

Taylor, M. A., and L. A. Clarke, 2018: Future Caribbean climates in a world of rising temperatures: The 1.5 vs. 2.0 dilemma. J. Climate, 31, 2907-2926, https://doi.org/10.1175/ JCLI-D-17-0074.1.

Wouters, H., and Coauthors, 2017: Heat stress increase under climate change twice as large in cities as in rural areas: A study for a densely populated midlatitude maritime region. Geophys. Res. Lett., 44, 8997-9007, https://doi.org/10.1002/ 2017GL074889. 